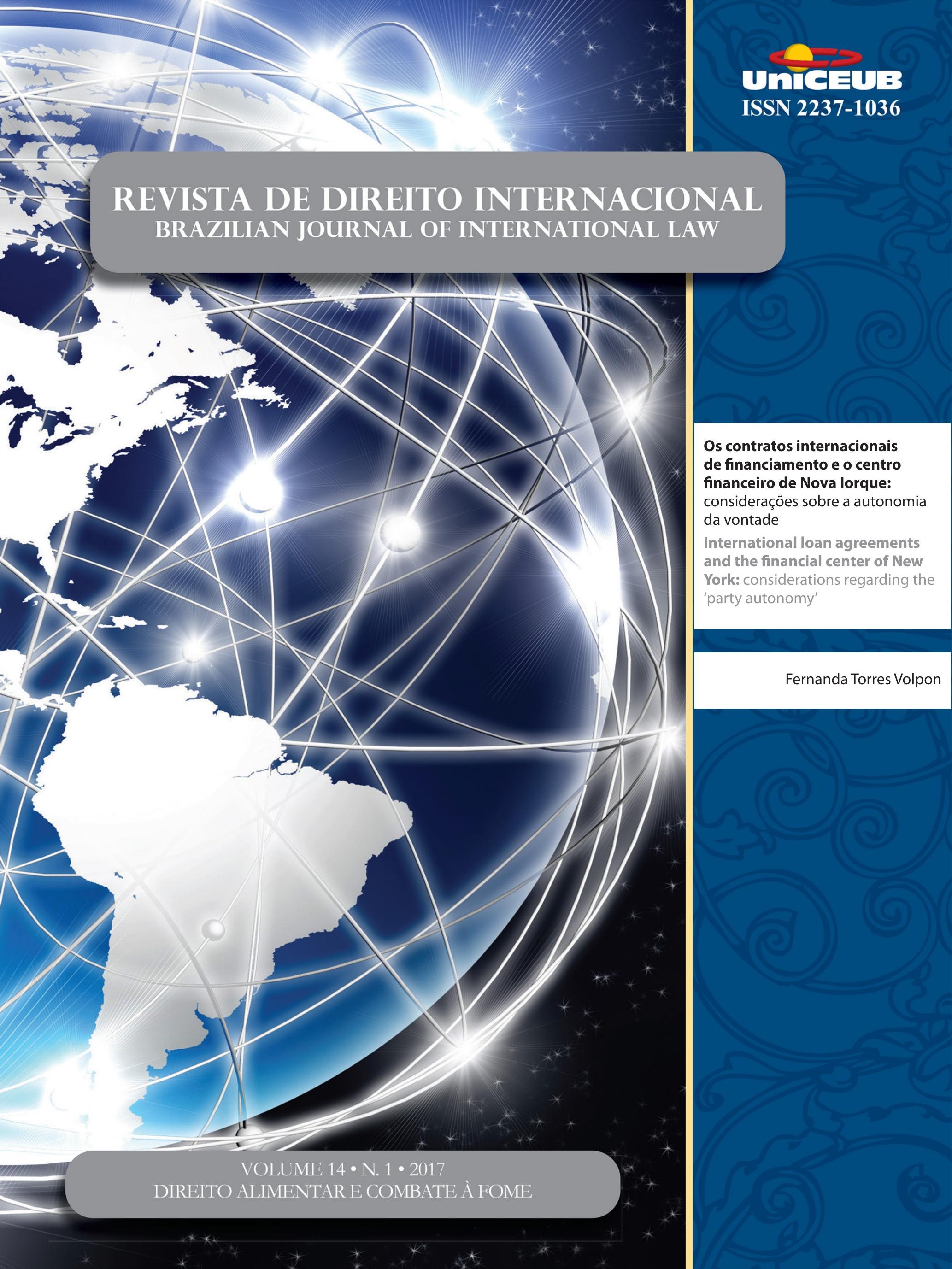




\section{Sumário}

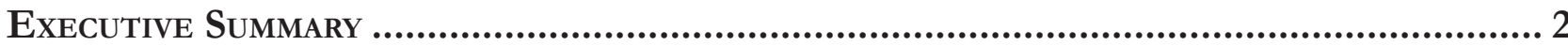

Daniel Balaban

Crônicas Sobre o Direito Alimentar e o Combate À Fome .............................................. 5

South-South Food and Nutrition Security promotion: the Brazilian experience

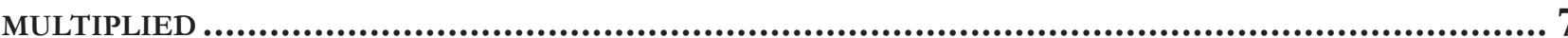

João Almino

Access to Food as a Human Right: Brazil, WFP and South-South Cooperation .......10 Carlos R. S. Milani

Dossiê temático: Direito Alimentar e Combate à Fome 13

WFP'S ROLE IN BUILDING SUSTAINABLE BRIDGES BETWEEN THE RIGHT TO ADEQUATE FOOD AND THE FREEDOM FROM HUNGER 15

Christiani Amaral Buani e Bruno Valim Magalhães

Direito humano À ALIMENTAÇÃo, (IN) SEgURANÇA ALIMENTAR E DESENVOLVIMENTO: OS DESAFios à REALIZAÇão PROGRESSIVA Na AMÉrica LATINa

Sinara Camera e Rubia Wegner

STATE'S INTERNATIONAL RESPONSIBILITY FOR THE HUMAN RIGHT TO FOOD: IMPLEMENTATION IN BRAZIL THROUGH AGROECOLOGY

Paula F. Strakos e Michelle B.B. Sanches

NegotiatiNg agRiCULtURE IN THE WORLD TRADE ORgANIZATION: FOOD SECURITY AS A NON-TRADE CONCERN.

Ana Luísa Soares Peres e Letícia de Souza Daibert

QUANDO HABITAR CORRESPONDE AO DIREITO HUMANO À ALIMENTAÇÃO

Fernanda Viegas Reichardt e Maria Elisa de Paula Eduardo Garavello 
The ROLE OF SUSTAINABLE LEARNING POLICIES ON THE FIGHT AGAINST

HUNGER IN ADULT EDUCATION.

Hiran Catuninho Azevedo

O DIREITO HUMANO E FUNDAMENTAL À ALIMENTAÇÃo ADEQUADA E À CONDIÇÃo

FEMININA NO PROGRAMA BOLSA FAMÍlIA: EMPODERAMENTO ÀS AVESSAS?

Rosalice Fidalgo Pinheiro e Laura Garbini Both

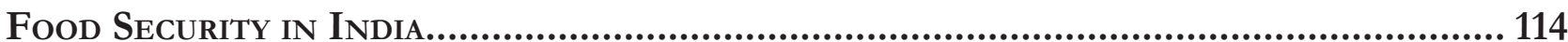

Ranjana Ferrão

SEguranÇA ALIMENTAR E A GOVERnANÇA ECONÔMICA GLOBAL

Danielle Mendes Thame Denny, Douglas de Castro, Alexandre Ricardo Machado, José Valverde Machado Filho e Gabrielle Fontes Witt

Outros Artigos.

The legal implications of the Draft Universal Declaration of the Rights of MANKIND

Catherine Le Bris

Litigating Indigenous Dispossession in THE Global Economy:

Law's Promises and Pitfalls................................................................................ 165

Charis Kamphuis

UNE DÉFINITION DU PRÉ-INVESTISSEMENT CONFORME À L'APPROCHE FRANÇAIS MAIS CONTRAIRE À L'APPROCHE AMÉRICAINE AU SEIN DES TRAITÉS BILATÉRAUX D'INVESTISSEMENTS IRANIENS

Peyman Dadras

CONFLITOS ENTRE REGULAÇÕES INTERNAS RELATIVAS À INTERNET E O DIREITO DO COMÉRCIO INTERNACIONAL: O PAPEL DA OMC PERANTE O SISTEMA DE COMPUTAÇÃO DA NUVEM ............238

Alice Rocha da Silva e Filipe Rocha Martins Soares

Prélèvement: origem, EVoluÇão e ocaso do Privilégio NAS SuCESSÕes INTERNACIONAIS NA FRANÇA

Fernando Pedro Meinero 
OS CONTRATOS INTERNACIONAIS DE FINANCIAMENTO E O CENTRO FINANCEIRO DE

Nova IorQue: CONSIDERAÇões SOBRE A AUTONOMIA DA VONTADE

Fernanda Torres Volpon

Mercosul e o Meio ambiente: ANÁlise da tUTELA REgional AMBIENTAL 284 Clarissa Ferreira Macedo D'Isep

Ainda (E uma Vez MAis) o SILÊNCIO QUe ENTOA O TRIUNFo De Lewis Carrol: A Regra N ${ }^{\circ} 42$ do Supremo Tribunal Federal

Thiago Aguiar Pádua e Bruno Amaral Machado

\section{A Natureza Jurídica do Sistema de Solução de Controvérsias da OMC} E DE SuAs Decisões: Solucionando um Imbróglio 316

Camila Capucio

Brics: Desafios do DESENVOLVIMENTO ECONÔMICO E SOCIOAMBIENTAI Magno Federici Gomes e Luís Eduardo Gomes Silva

REVER OU ROMPER COM VESTFÁLIA? POR UMA RELEITURA DA EFETIVA CONTRIBUIÇÃO DOS ACORDOS DE PAZ DE 1648 À CONSTRUÇÀO DO MODELO VESTFALIANO DE ESTADOS.

Luiz Magno Pinto Bastos Junior

Justiça de Transição EM SUA GÊNESE: A Alemanha Pós-NAZismo 378 Bruno Galindo

Quando JUlgar SE TORNa UM ESPETÁCulo: A INTERAÇão ENTRE o Supremo Tribunal Federal e a opinião pública, A PARTIR de REFlexões da LITERATURA ESTRANGEIRA

Patrícia Perrone Campos Mello

TolerânCia E refugio: um ENSAIO A PARTIR do ACORdo EU-TurQuia 425 Flávia Cristina Piovesan e Ana Carolina Lopes Olsen 


\title{
Os contratos internacionais de financiamento e o centro financeiro de Nova Iorque: considerações sobre a autonomia da vontade*
}

\author{
International loan agreements and the \\ financial center of New York: considerations \\ regarding the 'party autonomy'
}

Fernanda Torres Volpon **

\section{Resumo}

Este artigo possui como objetivo analisar o exercício da autonomia privada nos contratos internacionais de financiamento, verificando a hipótese de uma possível preferência pelo foro e leis de Nova Iorque e, caso exista, as razões para essa escolha e o problema do posicionamento dos tribunais norte-americanos em relação ao exercício da autonomia da vontade nessa espécie contratual. Aplica-se a metodologia jurídico-dogmática, utilizando-se como marco teórico a construção de um estudo dos temas da escolha da lei aplicável e eleição de foro permeado por uma análise empírica realizada pelos autores norte-americanos Theodore Eisenberg e Geoffrey Miller. Conclui-se que, não por acaso, os contratos internacionais de financiamento apresentam cláusulas de eleição de foro com competência para os tribunais de Nova Iorque, mesmo sem qualquer elemento de conexão com este território, tradicionais do Direito Internacional Privado. Evidencia-se, na verdade, uma 'corrida' dos atores privados para o centro financeiro de Nova Iorque influenciado, entre outros fatores, pelo resultado de um esforço político-regulatório do próprio Estado de Nova Iorque. O exercício da autonomia da vontade, nesse sentido, resulta de um processo de interesse econômico e desejo por segurança jurídica que os atores privados buscam na aplicação das leis de Nova Iorque nas suas controvérsias financeiras. $\mathrm{O}$ posicionamento dos tribunais de Nova Iorque coaduna com o interesse dos atores privados ao se auto-afirmarem como centro 'financeiro-judicial' e consagrarem o respeito pela escolha da lei e eleição do foro por partes estrangeiras sem apresentar um elemento de conexão, posicionamento este inovador em relação à tradicional doutrina do método de conflito de leis.

Palavras-Chave: Lei Aplicável. Eleição de Foro. Contratos de Financiamento. Autonomia da Vontade.

Recebido em 12/11/2016

Aprovado em 19/01/2017

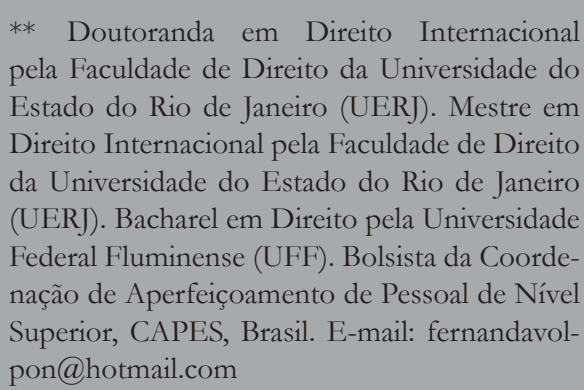

\section{Abstract}

This paper is focused on the analysis of the exercise of party autonomy in the international loan agreements, looking at the hypothesis of a real 
inclination for the forum and laws of New York by the contractual parties and, if existent, the reasons for such preference and the position of American courts in relation to the exercise of party autonomy in this type of agreements. The methodology applied in this paper is the dogmatic legal method, using the theory constructed by the study of choice of law and choice of forum influenced by the empirical analysis produced by the American authors Theodore Eisenberg e Geoffrey Miller. The conclusion demonstrates that, not by chance the international loan agreements include choice of forum clauses electing the New York State Courts without any relationship to the American territory a traditional element of international private law doctrine. In reality, it is possible to verify a 'race' by the private actors directed to the financial center of New. On the one hand, the exercise of party autonomy results in a process of economic interest and hunger for legal security that the private actors look for when applying the laws of New York to their financial disputes. On the other hand, New York Courts have positioned themselves in the same sense of private actors by auto declaring as the center of financial-judicial matters reaffirming that choice of law and choice of forum clauses made by foreign parties will prevail in the New York Courts without presenting a relationship with the American territory, an innovative position in relation to the traditional conflict of laws method.

Keywords: Governing Law. Choice of Forum. Loan Agreements. Party Autonomy.

\section{INTRODUÇÃO}

A negociação de contratos internacionais envolvendo vultuosas quantias e alto risco de retorno acabam por levar a um caminho tortuoso das batalhas das formas. ${ }^{1}$ As discussões negociais começam desde a proposta e perduram ao longo de toda a fase contratual. Trata-se de um embate dificultoso, que pode gerar consequências jurídicas relevantes para ambas as partes. ${ }^{2}$

1 RIBEIRO, Marilda Rosado de Sá. Batalha das formas e negociação prolongada nos contratos internacionais. In: RODAS, João Grandino (Coord.). Contratos Internacionais. 3. ed. rev. atual. e ampl. São Paulo: Revista dos Tribunais, 2002. p. 251-282, p. 264.

2 RIBEIRO, Marilda Rosado de Sá. Batalha das formas e negociação prolongada nos contratos internacionais. In: RODAS, João Grandino (Coord.). Contratos Internacionais. 3. ed. rev. atual. e ampl.
Ao longo do tempo, a conscientização dos operadores de mercado diante das dificuldades negociais culminou em uma necessária uniformização. Entende-se que trazer uniformidade para os contratos e suas cláusulas resultaria em eficiência, reduzindo custos para os envolvidos. Nessa esteira, conclui-se que a escolha de leis eficazes, sofisticadas e práticas gerariam segurança jurídica para que as partes tivessem a tão desejada previsibilidade nas suas transações comerciais. O impacto econômico dessas escolhas é evidente, tornando-se fator relevante não só para o departamento jurídico de diversas empresas, mas também para as suas áreas comerciais.

Compreendendo a necessidade do mercado, o Estado de Nova Iorque soube atrair as negociações e as discussões judiciais para o seu foro. Nova Iorque se tornou não só o centro financeiro, como também o centro judicial para as controvérsias no âmbito dos contratos internacionais de financiamento.

Assim, consolidaram-se as cláusulas de 'governing law'3 $^{3}$ e 'jurisdiction'4 para se aplicar as leis de Nova Iorque e se eleger o foro de Nova Iorque na grande maioria dos contratos comerciais. Essas Cláusulas se tornaram parte dos contratos padronizados das associações privadas para financiamentos internacionais. Além das instituições norte-americanas, diversos atores privados estrangeiros passaram a incluir essas cláusulas em seus contratos, sem que houvesse qualquer elemento de conexão com os Estados Unidos. Surgiu, então, o receio fundado sobre a reação dos tribunais a respeito do exercício da autonomia privada, problemática jurídica integrante deste trabalho. Surgiu o questionamento se os tribunais de Nova Iorque iriam respeitar a escolha das partes: valeria a autonomia da vontade mesmo quando não fosse identificado qualquer elemento de conexão na relação contratual com o território norte-americano?

Portanto, o objetivo deste trabalho consiste em (i) tratar das razões para os contraentes de transações "cross-border" ${ }^{5}$ optarem pelas cláusulas de lei aplicável

São Paulo: Revista dos Tribunais, 2002. p. 251-252.

3 Cláusula de lei aplicável (tradução livre).

4 Cláusula de eleição de foro (tradução livre).

5 No contexto desse trabalho, utiliza-se o termo "cross-border" para transações de financiamento envolvendo partes estrangeiras, sem elemento de conexão com o território norte-americano, caracterizadas como transfronteiriças. Neste caso, o credor e o devedor estariam fora dos Estados Unidos, mas a cláusula de eleição de foro e a escolha da lei aplicável seriam de Nova Iorque. "Como os contratos internacionais de empréstimo envolvem mais de uma jurisdição, os credores, na maioria das vezes, vão escolher a lei que eles consid- 
e eleição de foro integrantes nos modelos contratuais modernos, assim como (ii) analisar o posicionamento atual dos tribunais de Nova Iorque perante o exercício da autonomia da vontade nesses tipos contratuais.

Para tanto, esse trabalho foi dividido em três partes principais. Na primeira seção, procurou-se traçar um panorama sobre a autonomia da vontade na escolha da lei aplicável e eleição de foro. Neste primeiro momento, foram feitas breves considerações sobre como o tema é tratado no Brasil e no direito internacional para melhor compreensão do mesmo. A segunda seção discorre sobre a visão econômica determinante para escolha da lei aplicável aos contratos internacionais e eleição do foro. Ao contrário de se entender como uma decisão meramente jurídica, trata-se de um debate que alcança o nível comercial diante dos impactos financeiros que essa escolha pode causar. A terceira seção, por fim, traça os aspectos gerais sobre o direito norte-americano para definição de competência dos seus tribunais e se a autonomia da vontade na escolha da lei aplicável e eleição de foro do Estado de Nova Iorque é respeitada pelos tribunais nova-iorquinos. Procura-se traçar uma perspectiva sobre a motivação legislativa e reforma institucional realizada em Nova Iorque para atrair negócios e garantir a segurança jurídica para os operadores de mercado.

\section{Breves Considerações sobre Lei Aplicável e Eleição de Foro na Doutrina Brasileira}

O estudo mais aprofundado dos contratos internacionais de financiamento depende de algumas reflexões prévias sobre os aspectos fundamentais dos contratos internacionais: a escolha da lei aplicável e a eleição de foro. Não se objetiva travar discussões sobre a possibilidade de se exercer, no âmbito do direito brasileiro, a autonomia da vontade na celebração dos contratos internacionais, tema de antigo debate na doutrina, ${ }^{6}$ mas

eram mais benéfica". ROCHA, Dinir Salvador Rios de. Contrato de empréstimo internacional. São Paulo: Saraiva, 2013. p. 170. Observa-se, ainda, que as partes envolvidas nesses tipos de contratos são sofisticadas e não envolvem consumidores.

6 Nesse sentido, ver "uma das questões mais candentes no autal estágio de desenvolvimento do Direito Internacional Privado, notadamente no Brasil, é a incorporação do princípio da autonomia da vontade na celebração dos contratos internacionais, de forma a permitir aos contratantes a escolha da lei de regência de seu acordo, independentemente de outros elementos de conexão." NARDI, Marcelo de. Eleição de foro: Uma visão brasileira. In: RODAS, João sim apresentar seus aspectos fundamentais e posicionar esse tema de forma introdutória.

Preliminarmente, destaca-se que a escolha da lei aplicável não se confunde com a eleição de foro, já que a lei aplicável se refere ao direito que regerá a relação entre as partes e a interpretação das cláusulas contratuais. ${ }^{7} \mathrm{O}$ foro eleito, por sua vez, será aquele determinado para solucionar eventual controvérsia a respeito do contrato submetido a litígio, onde tramitará ação judicial. ${ }^{8}$ Os dois temas formam parte do núcleo da disciplina do direito internacional privado, ${ }^{9}$ disciplina esta que se preocupa em tratar dos conflitos de jurisdição em casos que apresentam elementos de estraneidade e conflitos de lei. Ambos os tópicos são de vital importância para que se determine "em que local acionar" e "qual a lei aplicável” ao caso vertente. ${ }^{10}$

Grandino (Coord.). Contratos Internacionais. 3. ed. rev. atual. e ampl. São Paulo: Revista dos Tribunais, 2002. p. 125. "Uma das questões mais discutidas em DIPr diz respeito à determinação da lei aplicável aos contratos internacionais". ARAUJO, Nadia de. A necessária mudança do artigo 9o da LINDB: o avanço que faltava para a consagração da autonomia da vontade no DIPr brasileiro. In: RAMOS, André de Carvalho (Org.). Direito Internacional Privado: Questões Controvertidas. Belo Horizonte: Arraes Editores, 2015. p. 289-309, p. 289. Sobre a controvérsia, ver também: FRANCESCHINI, José Inácio. A lei e o foro de eleição em tema de contratos internacionais. In: RODAS, João Grandino (Coord.). Contratos Internacionais. 3. ed. rev. atual. e ampl. São Paulo: Revista dos Tribunais, 2002. p. 6775. Nadia de Araujo trata do aspecto jurisprudencial em seu artigo. ARAUJO, Nadia de. Contratos Internacionais e a jurisprudência brasileira: Lei aplicável, ordem pública e cláusula de eleição de foro. In: RODAS, João Grandino (Coord.). Contratos Internacionais. 3. ed. rev. atual. e ampl. São Paulo: Revista dos Tribunais, 2002. p. 202-208. 7 "Curial é constatar a existência de duas liberdades essenciais na contratação internacional: 1.) a de escolher a lei aplicável ao contrato; e 2.) a de escolher o foro a que as partes submeter-se-ão para dirimir as disputas que possam surgir". Equanto a primeira é de direito material, a segunda é eminentemente de conotação processual. NARDI, Marcelo de. Eleição de foro: Uma visão brasileira. In: RODAS, João Grandino (Coord.). Contratos Internacionais. 3. ed. rev. atual. e ampl. São Paulo: Revista dos Tribunais, 2002. p. 129. Carmen Tiburcio e Jacob Dolinger também ressaltam que "a determinação da lei aplicável é, portanto, assunto distinto da competência jurisdicional e não se podem confundir esses dois objetos". DOLINGER, Jacob; TIBURCIO, Carmen. Direito Internacional Privado: Parte Geral e Processo Internacional. 12. ed. rev. atual. e ampl. Rio de Janeiro: Forense, 2016. p. 556.

8 GARCIA JUNIOR, Armando Alvares. Lei aplicável aos contratos internacionais. 2. ed. São Paulo: Aduaneiras, 2004. p. 6-7.

9 "O Direito Internacional Privado possui, como visto anteriormente, quatro objetos de estudo distintos. Entre estes destacam-se a determinação da lei aplicável às relações jurídicas interjurisdicionais e, no âmbito do direito processual internacional, a fixação da competência internacional da autoridade judiciaria local”. DOLINGER, Jacob; TIBURCIO, Carmen. Direito Internacional Privado: Parte Geral e Processo Internacional. 12. ed. rev. atual. e ampl. Rio de Janeiro: Forense, 2016. p. 556.

10 ARAUJO, Nadia de. Direito Internacional Privado: Teoria e 
Respeitando o critério cronológico da disciplina de processo civil internacional, ${ }^{11}$ decidiu-se por realizar a análise, em primeiro lugar, da "fixação da competência internacional" e, em segundo lugar, da determinação da lei aplicável.

A dificuldade de se tratar do tema da eleição de foro se deve ao fato de que esse tema encontra-se na "seara do direito público, na medida em que se cuida do exercício da atividade jurisdicional, uma das funções da soberania do Estado". ${ }^{12}$ No entanto, não se pode deixar de reconhecer a importância do exercício da autonomia da vontade dos atores privados nesse cenário.

Quanto à eleição de foro, destaca-se que existem duas possibilidades de exercício da autonomia da partes: positiva e negativa. Nesse sentido, esclarecem Jacob Dolinger e Carmen Tibúrcio:

as partes podem atuar tanto inserindo hipótese não prevista na norma interna sobre o exercício da função jurisdicional (efeitos positivos) quanto afastando a jurisdição, em hipótese prevista na legislação local, com escolha de foro estrangeiro para conhecer do litígio (efeitos negativos. ${ }^{13}$

No direito brasileiro, o legislador determinou as hipóteses de competência internacional concorrente da jurisdição brasileira nos artigos 21 e 22 do Código de Processo Civil de $2015^{14}$ e competência internacional exclusiva no artigo 23 do mesmo diploma legal. Nádia de Araújo destaca que, a cláusula de eleição de foro deve ser analisada juntamente com as regras de competência internacional previstas no Código de Processo Civil brasileiro (CPC).$^{15}$ Isto porque, nos casos de competência internacional exclusiva da jurisdição brasileira, a de-

Prática Brasileira. 6a ed., atual. e ampl. Porto Alegre: Revolução eBook, 2016, p. 77-78.

11 DOLINGER, Jacob; TIBURCIO, Carmen. Direito Internacional Privado: Parte Geral e Processo Internacional. 12. ed. rev. atual. e ampl. Rio de Janeiro: Forense, 2016. p. 556.

12 DOLINGER, Jacob; TIBURCIO, Carmen. Direito Internacional Privado: Parte Geral e Processo Internacional. 12. ed. rev. atual. e ampl. Rio de Janeiro: Forense, 2016. p. 570.

13 DOLINGER, Jacob; TIBURCIO, Carmen. Direito Internacional Privado: Parte Geral e Processo Internacional. 12. ed. rev. atual. e ampl. Rio de Janeiro: Forense, 2016. p. 570.

14 Destaca-se que as hipóteses do artigo 88 do Código de Processo Civil de 1973 foram fielmente reproduzidas no art. 21 do Código de Processo Civil de 2015 (CPC de 2015). No entanto, novas hipóteses foram acrescentadas no art. 22 do CPC de 2015 sem correspondência com o CPC anterior.

15 ARAUJO, Nadia de. Contratos Internacionais e a jurisprudência brasileira: Lei aplicável, ordem pública e cláusula de eleição de foro. In: RODAS, João Grandino (Coord.). Contratos Internacionais. 3. ed. rev. atual. e ampl. São Paulo: Revista dos Tribunais, 2002. p. 213. cisão estrangeira não terá eficácia. ${ }^{16}$

Nos casos de competência internacional concorrente, a doutrina brasileira, de forma majoritária, admitia a eleição de foro indistintamente quanto àquelas com efeitos positivos e negativos. ${ }^{17}$ Por outro lado, a jurisprudência tomou posicionamentos controvertidos no momento de julgar contratos que apresentavam cláusula de eleição de foro. ${ }^{18}$ Diante da instabilidade das decisões do Superior Tribunal de Justiça (STJ), as partes acaba-

16 "se a cláusula referente à escolha de outro foro for pactuada considerando alguma das competências arroladas no artigo 89, a cláusula não seria válida, pois estaria usurpando do Estado o seu exercício de atividade jurisdicional". XAVIER JUNIOR, Ely Caetano; CASTRO, Emília Lana de Freitas. A competência internacional e a eleição de foro no projeto do novo código de processo civil brasileiro. Revista do Instituto do Direito Brasileiro, Lisboa, ano 2, n. 8, p. 79858022, 2013. Disponível em: < http://www.cidp.pt/publicacoes/ revistas/ridb/2013/08/2013_08_07985_08022.pdf>. Acesso em: 03 out. 2016. p. 8012.

17 Luiz Olavo Baptista trata de aspectos teoricos e práticos do tema. BAPTISTA, Luiz Olavo. Dos contratos internacionais: uma visão teórica e prática. São Paulo: Saraiva, 1994. p. 48-49. SOUZA JUNIOR, Lauro da Gama. Autonomia da vontade nos contratos internacionais no Direito Internacional Privado brasileiro: Uma leitura constitucional do artigo $9^{\circ}$ da Lei de Introdução ao Código Civil em favor da liberdade de escolha do direito aplicável. In: TIBURCIO, Carmen; BARROSO, Luís Roberto (Org.). O direito internacional contemporâneo: estudos em homenagem ao professor Jacob Dolinger. Rio de Janeiro: Renovar, 2006. p. 605-608. Carmen Tiburcio cita os doutrinadores Serpa Lopes, Haroldo Valladão, Helio Tornaghi, Irineu Strenger, Arruda Alvim, Nadia de Araújo, entre outros, como favoráveis à cláusula de eleição de foro. TIBURCIO, Carmen. A eleição de foro estrangeiro e o judiciario brasileiro. Revista de Arbitragem e Mediação, São Paulo, v. 6, n. 21, p. 84-113, abr./jun. 2009. Lembra, ainda, que em posição oposta, contrariamente à admissão da cláusula de eleição de foro. DOLINGER, Jacob; TIBURCIO, Carmen. Direito Internacional Privado: Parte Geral e Processo Internacional. $12^{\mathrm{a}}$ ed. rev., atual. e ampl. Rio de Janeiro: Forense, 2016, p. 575 .

18 Destacam os autores que, na década de 50, o Supremo Tribunal Federal "assumiu posição inovadaora e admitiu expressamente a escolha de foro uruguaio em contrato celebrado para ser cumprido no Brasil". No entanto, como ressaltam os autores, diversas decisões do STJ posteriores desconsideraram a eleição de foro estrangeiro. DOLINGER, Jacob; TIBURCIO, Carmen. Direito Internacional Privado: Parte Geral e Processo Internacional. 12. ed. rev. atual. e ampl. Rio de Janeiro: Forense, 2016. p. 575. Nádia de Araújo destaca o posicionamento incerto da jurisprudência brasileira no tocante à consagração da cláusula de eleição de foro: "Até então, a possibilidade de a Justiça brasileira ceder ou não espaço a um foro estrangeiro escolhido pelas partes era objeto de controvérsias, adotando os tribunais um posicionamento vacilante, que ora aceitava a escolha das partes e ora decidia que as regras do artigo 88 não autorizavam o afastamento da atuação da Justiça nacional diante de uma das hipóteses de competência concorrente". ARAUJO, Nadia; SPTIZ, Lidia; NORONHA, Carolina. O novo CPC nas relações internacionais. Jornal Valor Econômico, 13 de jan. de 2015. Disponível em: <http://www.valor.com.br/legislacao/3856442/o-novo-cpc-nasrelacoes-internacionais>. Acesso em 04 out. 2016. 
vam por se sentirem inseguras "no momento da celebração de contratos com elementos de estraneidade", 19 uma vez que não saberiam assegurar se a eleição de foro seria respeitada ou não pelo judiciário brasileiro.

O CPC de 2015, por sua vez, consagrou a possibilidade do exercício da autonomia privada no tocante à eleição de foro. ${ }^{20}$ Dessa forma, o referido diploma permitiu a eleição de foro com efeitos positivos no âmbito do artigo 22, "acarretando a competência concorrente do Judiciário brasileiro" 21 e, com efeitos negativos no âmbito do artigo 25 "que ensejam a incompetência do Judiciário brasileiro quando houver foro eleito no exterior". ${ }^{22}$ Observa-se que, a escolha do foro deve ser exclusiva, nos termos do artigo 25 do CPC de 2015. Assim, existem dois requisitos para a validade da cláusula de eleição de foro: "o acordo seja expresso e ainda explicite que se trata de uma cláusula exclusiva", ${ }^{23}$ com objetivo de se evitar que a eleição de foro seja interpretada como "mera obrigação de fazer".

Portanto, conclui-se que o tema da possibilidade de as partes determinarem de forma prévia o foro ao qual consideram mais conveniente submeter sua controvérsia, encontra-se, nesse momento, sanado pelo advento do CPC de 2015. Deve-se acompanhar o posicionamento da jurisprudência para verificar se o tema será consagrado também nessa seara.

Em paralelo, destaca-se a aceitação da eleição de foro no plano internacional, preceito consagrado na

19 XAVIER JUNIOR, Ely Caetano; CASTRO, Emília Lana de Freitas. A competência internacional e a eleição de foro no projeto do novo código de processo civil brasileiro. Revista do Instituto do Direito Brasileiro, Lisboa, ano 2, n. 8, p. 7985-8022, 2013. Disponível em: < http://www.cidp.pt/publicacoes/revistas/ridb/2013/08/20 13_08_07985_08022.pdf>. Acesso em: 03 out. 2016. p. 8017.

20 "A grande novidade é a inclusão de um relevante permissivo: agora, é inconteste a possibilidade de as partes afastarem a competência da Justiça brasileira por meio da eleição de foro estrangeiro exclusivo em seus contratos". ARAUJO, Nadia; SPTIZ, Lidia; NORONHA, Carolina. O novo CPC nas relações internacionais. Jornal Valor Econômico, 13 de jan. de 2015. Disponível em: $<$ http://www.valor.com.br/legislacao/3856442/o-novo-cpc-nasrelacoes-internacionais>. Acesso em 04 out. 2016.

21 DOLINGER, Jacob; TIBURCIO, Carmen. Direito Internacional Privado: Parte Geral e Processo Internacional. 12. ed. rev. atual. e ampl. Rio de Janeiro: Forense, 2016. p. 577.

22 DOLINGER, Jacob; TIBURCIO, Carmen. Direito Internacional Privado: Parte Geral e Processo Internacional. 12. ed. rev. atual. e ampl. Rio de Janeiro: Forense, 2016. p. 577.

23 ARAUJO, Nadia de. Direito Internacional Privado: Teoria e Prática Brasileira. 6. ed. atual. e ampl. Porto Alegre: Revolução eBook, 2016. p. $367-268$
Convenção de Haia sobre Eleição de Foro de $2005,{ }^{24}$ assim como em outros instrumentos. O Regulamento $\mathrm{n}^{\circ}$ 1215 de 2012 da União Europeia estabeleceu a competência exclusiva do tribunal de um Estado-membro "se as partes, independentemente do seu domicílio, tiverem convencionado que um tribunal ou os tribunais de um Estado-Membro têm competência para decidir quaisquer litígios que tenham surgido ou que possam surgir de uma determinada relação jurídica". ${ }^{25}$ No âmbito do Mercosul, o artigo $4^{\circ}$ do Protocolo de Buenos Aires sobre Jurisdição Internacional em Matéria Contratual, promulgado pelo Decreto no. 2.095/1996, ${ }^{26}$ também consagrou a possibilidade de acordo para submissão à jurisdição dos tribunais de Estados-Partes do Mercosul no âmbito dos contratos internacionais em matéria civil ou comercial. Nos Estados Unidos, já na década de 1970, a Suprema Corte dos Estados Unidos entendeu no caso Bremen v. Zapata Off-Shore Company, pelo respeito de uma cláusula de eleição de foro com jurisdição exclusiva para os tribunais norte-americanos. ${ }^{27}$

24 HCCH. Convention of 30 June 2005 on Choice of Court Agreements. Disponível em: <https://www.hcch.net/en/instruments/conventions $/$ full-text $/$ ?cid=98>. Acesso em: 04 out. 2016. Destaca-se que tal Convenção "procurou conferir previsibilidade em questão de jurisdição internacional, mas assegurar igualdade de condições à cláusula de escolha de foro [...], privilegiando o princípio da autonomia da vontade". CASTRO, Joana Holzmeister. Cláusula de Eleição de Foro em Contratos Internacionais: o que muda com o novo Código de Processo Civil. 2015. 57 f. Monografia (Graduação em Direito) - Faculdade de Direito, Pontifícia Universidade Católica do Rio de Janeiro, Rio de Janeiro, 2005. p. 30.

25 Exceções para a competência exclusiva do foro eleito estão previstas no próprio artigo 25 (1) do Regulamento "a menos que o pacto seja, nos termos da lei desse Estado-Membro, substantivamente nulo. Essa competência é exclusiva, salvo acordo das partes em contrário." UNIÃO EUROPÉIA. Regulamento (UE) no 1215 do Parlamento Europeu e do Conselho de 12 de dezembro 2012. Disponível em: <http://eur-lex.europa.eu/LexUriServ/LexUriServ.do?uri=OJ :L:2012:351:0001:0032:pt:PDF>. Acesso em: 04 out. 2016.

26 BRASIL. Protocolo de Buenos Aires sobre Jurisdição Internacional em Matéria Contratual. Disponível em: <http://www.camara.leg.br/ mercosul/Protocolos/BUENOS_AIRES.htm>. Acesso em: 04 out. 2016.

27407 U.S. 1 (1972). As partes (uma empresa alemã e norteamericana) celebraram um contrato para rebocar um equipamento de perfuração de Louisiana para Itália que incluía uma cláusula determinando que qualquer disputa seria submetida aos tribunais da Inglaterra. Durante o transporte, uma tempestade danificou o equipamento e forçou a companhia rebocadora a atracar na Florida. Com isso, a empresa norte-americana processou no tribunal da Florida. A empresa alemã demandou que a cláusula determinando a competência exclusiva dos tribunais ingleses fosse respeitada. A Suprema Corte entendeu que era válida a cláusula, a não ser que a parte ré demonstrasse que declarar a cláusula válida seria injusto ou desproporcional. Disponível: <http://caselaw.findlaw.com/ussupreme-court/407/1.html>. Acesso em 06 out. 2016. 
A escolha da lei aplicável é um tema submetido à debate doutrinário com semelhante controvérsia presente no caso da eleição de foro. Deve-se esclarecer que a determinação da lei aplicável se faz a partir das regras de conexão, após tenha sido determinada a jurisdição competente. Carmen Tibúrcio e Jacob Dolinger as definem como "normas solucionadoras de conflitos de leis". ${ }^{28}$ Cada país tem o seu conjunto de regras para determinar qual a lei aplicável de acordo com os seus critérios de conexão.

No âmbito dos contratos internacionais, a regra de conexão brasileira é aquela elencada no artigo $9^{\circ}$ do Decreto-Lei 4.657 de 4 de setembro de 1942 (Lei de Introdução às Normas do Direito Brasileiro - LINDB) ${ }^{29}$, a qual estabelece a lei do local de celebração (lex loci contractus) para qualificar e reger as obrigações. ${ }^{30}{ }^{31}$

No entanto, a controvérsia no direito brasileiro versa

28 DOLINGER, Jacob; TIBURCIO, Carmen. Direito Internacional Privado: Parte Geral e Processo Internacional. 12. ed. rev. atual. e ampl. Rio de Janeiro: Forense, 2016. p. 557.

29 BRASIL. Decreto-Lei no 4.657, 4 de Setembro de 1942 (Redação dada pela Lei $n^{\circ} 12.376$, de 2010). Disponível em: < http://www. planalto.gov.br/ccivil_03/decreto-lei/Del4657compilado.htm>. Acesso em 04 out. 2016.

30 ARAUJO, Nadia de. Direito Internacional Privado: Teoria e Prática Brasileira. 6. ed. atual. e ampl. Porto Alegre: Revolução eBook, 2016. p. 81.

31 A título de esclarecimento, o artigo 21, III do CPC 2015 menciona "ato ocorrido no Brasil". "Art. 21. Compete à autoridade judiciária brasileira processar e julgar as ações em que: III - o fundamento seja fato ocorrido ou ato praticado no Brasil.”. Jacob Dolinger e Carmen Tiburcio fazem uma interpretação deste artigo para considerar a competência internacional concorrente no caso de contrato celebrado no Brasil. DOLINGER, Jacob; TIBURCIO, Carmen. Direito Internacional Privado: Parte Geral e Processo Internacional. 12. ed. rev. atual. e ampl. Rio de Janeiro: Forense, 2016. p. 563. Nessa esfera, importante traçar um paralelo para a previsão competência internacional (jurisdição) concorrente consubstanciada nos termos do artigo 21, III do CPC de 2015. Essa disposição prevê que a competência da jurisdição brasileira no caso de o contrato ter sido celebrado no território brasileiro. Destaca-se que, o Brasil é visto isoladamente no tocante a essa previsão. Foram realizadas pesquisas no âmbito da União Europeia (Regulamento no. 1215/2012), Portugal (Código de Processo Civil de 2013), França (Código de Processo Civil e Código Civil) e Estados Unidos (Jurisprudência) não possuem disposição equivalente para competência internacional. UNIÃO EUROPÉIA. Regulamento (UE) $n^{\circ} 1215$ do Parlamento Europeu e do Conselho de 12 de dezembro 2012. Disponível em: <http:/ / eur-lex.europa.eu/LexUriServ/LexUriServ.do?uri=OJ:L:2012:351: 0001:0032:pt:PDF>. Acesso em: 04 out. 2016; PORTUGAL. Lei $n^{\circ}$ 41/2013, de 26 de junbo. Disponível em: <http://www.pgdlisboa. pt/leis/lei_mostra_articulado.php?nid=1959\&tabela=leis $>$. Acesso em: 04 out. 2016; FRANÇA. Code de Procédure Civile. <https:// www.legifrance.gouv.fr $/$ affichCode.do;jsessionid $=0$ F2723F52018 03CF911ECAB5A3705687.tpdila13v_3?idSectionTA=LEGISCT A000006135862\&cidTexte $=$ LEGITEXT000006070716\&dateTex te $=20161004>$. Acesso em: 04 out. 2016 . sobre o fato de as partes deterem ou não autonomia da vontade no tocante à escolha da lei aplicável ou se deverá ser aplicada a lei onde a obrigação foi constituída, ${ }^{32}$ já que "essa autonomia é vista de forma controversa na doutrina brasileira e jurisprudência". ${ }^{33}$ Uma das razões para essa discussão se consolidou no fato de que o artigo $9^{\circ}$ da LINDB omite o termo "salvo estipulação em contrário" presente no texto do artigo 13 da antiga Lei de Introdução ao Código Civil. ${ }^{34}$

Enquanto no direito brasileiro, muito se discutiu acerca da possibilidade do exercício da autonomia da vontade na escolha da lei aplicável, "no plano internacional, pode-se dizer que há um consenso de que cabe às partes escolher o direito aplicável, consagrado o princípio da autonomia da vontade". ${ }^{35}$ Os princípios da Conferência da Haia sobre escolha da lei aplicável em contratos comerciais aplica a autonomia da vontade, demonstrando a amplitude da aceitação desse princípio

32 RIBEIRO, Marilda Rosado de Sá. Batalha das formas e negociação prolongada nos contratos internacionais. In: RODAS, João Grandino (Coord.). Contratos Internacionais. 3. ed. rev. atual. e ampl. São Paulo: Revista dos Tribunais, 2002. p. 253.

33 Nesse sentido, "a autonomia da vontade não pode ser reconhecida como elemento de conexão contratual". FRANCESCHINI, José Inácio. A lei e o foro de eleição em tema de contratos internacionais. In: RODAS, João Grandino (Coord.). Contratos Internacionais. 3. ed. rev. atual. e ampl. São Paulo: Revista dos Tribunais, 2002. p. 71. Nesse sentido, ver o Artigo 9 da atual Lei de Introdução às normas do Direito Brasileiro "Art. $9^{\circ}$ Para qualificar e reger as obrigações, aplicar-se-á a lei do país em que se constituirem. $\int 1^{\circ}$ Destinando-se a obrigação a ser executada no Brasil e dependendo de forma essencial, será esta observada, admitidas as peculiaridades da lei estrangeira quanto aos requisitos extrínsecos do ato. $\$ 2^{\circ}$ A obrigação resultante do contrato reputa-se constituida no lugar em que residir o proponente." Carmen Tiburcio ressalta que "No Brasil, como regra, os contratos são regidos pela lei do lugar da sua celebração - lex loci celebrationis - havendo controvérsia na doutrina acerca da possibilidade de escolha pelas partes da lei aplicável - lex voluntatis.". Para tanto, cita na doutrina que, enquanto alguns entendem que a doutrina da autonomia da vontade é inadmissível - Amilcar de Castro, Irineu Strenger, Oscar Tenório - outros entendem que a autonomia da vontade é consagrada no direito internacional privado brasileira - Haroldo Valladão. TIBURCIO, Carmen. A arbitragem como meio de solução de litígios comerciais internacionais envolvendo o petróleo e uma breve análise da cláusula arbitral da sétima rodada de licitações da ANP. Revista de Arbitragem e Mediação, São Paulo, v. 3, n. 9, p. 78-98, abr./jun. 2006. p.84-85.

34 "Art. 13. Regulará, salvo estipulação em contrário, quanto á substância e aos efeitos das obrigações, a lei do lugar, onde forem contraídas.” BRASIL. Lei n 3.071, de $1^{\circ}$ de janeiro de 1916. Disponível em: <http://www.planalto.gov.br/ccivil_03/leis/L3071.htm>. Acesso em 03 out 2016.

35 ARAUJO, Nadia de. A necessária mudança do artigo 9o da LINDB: o avanço que faltava para a consagração da autonomia da vontade no DIPr brasileiro. In: RAMOS, André de Carvalho (Org.). Direito Internacional Privado: Questões Controvertidas. Belo Horizonte: Arraes Editores, 2015. p. 289. 
pelos Estados-contratantes. ${ }^{36}$ A Convenção Interamericana sobre Direito Aplicável aos Contratos Internacionais também consagrou em seu artigo $7^{\circ}$ a possibilidade de escolha aplicável pelas partes, determinando que "O contrato rege-se pelo direito escolhido pelas partes". ${ }^{37}$ No plano europeu, o Regulamento nº 593/2008 da União Europeia sobre a lei aplicável às obrigações contratuais (Roma I), prevê a possibilidade de escolha da lei aplicável pelas partes no seu artigo $3^{\circ}$. Nesse caso, a escolha também deverá "ser expressa ou resultar de forma clara das disposições do contrato, ou das circunstâncias do caso" ${ }^{38}$ Nos Estados Unidos, a supremacia da autonomia da vontade foi resultado de um debate que durou anos e se encerrou algumas décadas atrás ${ }^{39}$ sendo que, atualmente, o seu exercício encontra-se consagrado no Restatement (Second) $\int 187$ e UCC $\int 1-105 . .^{40}$

Nessa esteira, defende-se a necessidade de revisitação das normas sobre a escolha da lei aplicável no direito brasileiro. Nádia de Araújo trata da proposta de mudança do artigo $9^{\circ}$ da LINDB introduzida pelas emendas ao Projeto de Lei nº. 281 de 2012 aprovado no Senado Federal e encaminhado para aprovação da Câmara de Deputados em novembro de 2015.

Essa proposta insere o artigo $9^{\circ}-\mathrm{A}$ na LINDB, em que se permite que "o contrato internacional entre profissionais, empresários e comerciantes reger-se-á pela lei escolhida pelas partes, devendo esta escolha referir-se à

36 "Many States have reached this conclusion and, as a result, giving effect to party autonomy is the predominant view today.". HCCH. Convention of 30 June 2005 on Choice of Court Agreements. Disponível em: <https:/ / www.hcch.net/en/instruments/conventions/full-text/?cid=98>. Acesso em: 04 out. 2016.

37 "O acordo das partes sobre esta escolha deve ser expresso ou, em caso de inexistência de acordo expresso, depreender-se de forma evidente da conduta das partes e das cláusulas contratuais, consideradas em seu conjunto. Essa escolha poderá referir-se à totalidade do contrato ou a uma parte do mesmo." ORGANIZAÇÃO DOS ESTAOS AMERICANOS. Convenção Interamericana sobre Direito Aplicável aos Contratos Internacionais. Disponível em: <http:// www.oas.org/juridico/portuguese/treaties/b-56.htm>. Acesso em: 04 out. 2016. Ressalta-se que essa Convenção encontra-se ratificada apenas pelo México e Venezuela.

38 UNIAO EUROPEIA. Regulamento (ce) n.o 593/2008 do Parlamento Europeu e do Conselho de 17 de junbo de 2008. Disponível em: $<$ http://eur-lex.europa.eu/LexUriServ/LexUriServ.do?uri=OJ:L:2 008:177:0006:0016:PT:PDF>. Acesso em: 04 out. 2016.

39 RUHL, Giesela. Party Autonomy in the Private International Law of Contracts: Transatlantic Convergence and Economic Efficiency. CLPE Research Paper 4/2007, v. 3, n. 1, p. 1-41, 2007. p. 4.

40 RUHL, Giesela. Party Autonomy in the Private International Law of Contracts: Transatlantic Convergence and Economic Efficiency. CLPE Research Paper 4/2007, v. 3, n. 1, p. 1-41, 2007. p. 4. totalidade do contrato e ser efetuada mediante acordo expresso entre as partes". ${ }^{41}$

Dessa forma, observa-se que o caput do artigo $9^{\circ}$-A reproduzido acima "adotou expressamente o princípio da autonomia da vontade, ao dispor ser a lei aplicável ao contrato internacional aquelas escolhida pelas partes". ${ }^{42}$ Nesse sentido, caso seja aprovado o referido Projeto de Lei, consagra-se a autonomia da vontade entre as partes contratantes no direito brasileiro, mesmo que "sem conexão com as partes ou a transação. Isso reforça o princípio da autonomia das partes no sentido de ser escolhida uma lei neutra ou especializada, mais adequada à transação e não tão somente uma lei que seja próxima das partes". ${ }^{43}$ Por fim, é preciso destacar que a nova disposição se aplicaria a contratos internacionais destinados às relações comerciais e não se aplicaria às relações de consumo e de trabalho.

Essa previsão, juntamente com a nova disposição do CPC de 2015 para eleição de foro, permitiria que o Brasil se aproximasse das jurisdições que possuem uma visão mais consolidada da autonomia da vontade, estimulando o fluxo de comércio internacional e investimento estrangeiro. A consagração da autonomia da vontade no ordenamento jurídico brasileiro permitirá que as partes brasileiras e estrangeiras sintam maior segurança jurídica quanto ao sistema brasileiro. Na próxima seção, será tratado do aspecto econômico que fundamenta a escolha da lei aplicável e eleição de foro nos contratos internacionais.

\section{VISÃo ECONÔMICA dA ESCOLHA DA LEI APLICÁVEL E ELEIÇÃO DE FORO NOS CONTRATOS INTERNACIONAIS}

Com a mundialização da economia, a expansão do comércio internacional, mobilidade de pessoas, transfe-

41 BRASIL. Projeto de Lei $n^{\circ} .281$ de 2012. Disponível em: <http://www.senado.leg.br/atividade/rotinas/materia/getPDF. asp?t=182349\&tp=1>. Acesso em: 04 out. 2016. p. 9.

42 ARAUJO, Nadia de. A necessária mudança do artigo 9o da LINDB: o avanço que faltava para a consagração da autonomia da vontade no DIPr brasileiro. In: RAMOS, André de Carvalho (Org.). Direito Internacional Privado: Questões Controvertidas. Belo Horizonte: Arraes Editores, 2015. p. 301.

43 ARAUJO, Nadia de. A necessária mudança do artigo 9o da LINDB: o avanço que faltava para a consagração da autonomia da vontade no DIPr brasileiro. In: RAMOS, André de Carvalho (Org.). Direito Internacional Privado: Questões Controvertidas. Belo Horizonte: Arraes Editores, 2015. p. 303. 
rências de tecnologia e ampliação da capacidade de investimento, se desenvolveu o processo de globalização, alcançando diversos setores da economia.

De certa forma, a globalização estreitou os laços entre atores do mercado internacional, consolidando-se como um fenômeno que

\begin{abstract}
aproximou os mercados, o comércio realiza-se agora - cada vez mais - entre pessoas e empresas de diversos países, com diversas sedes e filiais, com marcas e imagens consolidadas, com empresas de capital muitas vezes disperso entre acionistas de muitas nacionalidades e países, mas de atuação e produção realmente multinacional. ${ }^{44}$
\end{abstract}

Todavia, esse fenômeno incorpora-se através do seu caráter "multidimensional", ${ }^{45}$ que apresenta um alto nível de complexidade e relaciona diferentes "domínios da atividade e das interações humanas" ${ }^{46}$ Globalização é um processo híbrido e complexo. Os seus efeitos jurídicos não podem ser justificados a partir de um simples argumento fático ou legal..$^{47}$

O resultado natural do processo globalizante culminou em aumento significativo no número de empresas que, através de suas subsidiárias e filiais, permeiam os polos econômicos de diversos países, dos menos aos mais desenvolvidos. Desse modo, o processo de múltiplas conexões e aproximação das relações empresariais impulsionou uma expansão além-fronteiras das sociedades que se globalizaram e ampliaram suas atividades "para além das barreiras territoriais de seu Estado de origem". ${ }^{48}$

44 MARQUES, Cláudia Lima. Ensaio para uma introdução ao Direito Internacional Privado. In: DIREITO, Carlos Alberto Menezes; TRINDADE, Antônio Augusto Cançado; PEREIRA, Antonio Celso Alves. (Coord.). Novas perspectivas do direito internacional contemporâneo: Estudos em homenagem ao professor Celso D. de Albuquerque Mello. Rio de Janeiro: Renovar, 2008. p. 326.

45 BARRETTO, Vincente de Paulo. Globalização, direito cosmopolítico e direitos humanos. In: DIREITO, Carlos Alberto Menezes; TRINDADE, Antônio Augusto Cançado; PEREIRA, Antônio Celso Alves. Novas perspectivas do direito internacional contemporâneo: Estudos em homenagem ao Professor Celso D. de Albuquerque Mello. Rio de Janeiro: Renovar, 2008. p. 943.

46 BARRETTO, Vincente de Paulo. Globalização, direito cosmopolítico e direitos humanos. In: DIREITO, Carlos Alberto Menezes; TRINDADE, Antônio Augusto Cançado; PEREIRA, Antônio Celso Alves. Novas perspectivas do direito internacional contemporaneo: Estudos em homenagem ao Professor Celso D. de Albuquerque Mello. Rio de Janeiro: Renovar, 2008. p. 943.

47 BERGER, Klaus Peter. Transnational Commercial Law in the Age of Globalization. In: SAGGI, CONFERENZE E SEMINARI 42, Disponível em: < http://cisgw3.law.pace.edu/cisg/biblio/berger1.html>. Acesso em 03 out. 2016. p. 3.

48 XAVIER, Mônica Antão. Internacionalização de Empresas e
No seio de uma economia transnacionalizada, se torna um tema de fundamental análise: o caráter econômico das decisões dos atores privados sobre a lei aplicável e eleição de foro, escolhas fundamentais nos contratos internacionais. Nesse cenário, verifica-se um fenômeno recorrente em que se busca a redução dos custos das transações e aumento da sua eficiência. ${ }^{49}$ Klaus Berger ressalta que a aplicação das leis nacionais em transações comerciais transnacionais sempre foi analisada como um obstáculo imposto ao mercado globalizado devido ao seu custo: "the application of foreign law is regarded as the 'globalization trap', the devision of the world into different legal systems can be regarded as a non-tariff trade barrier". ${ }^{50}$

Dentre um dos desenvolvimentos jurídicos relevantes para a transnacionalização do direito comercial, destaca-se a consagração da autonomia da vontade no direito internacional, além da consolidação do entendimento de que as tecnicidades da legislação doméstica não se adequam ao comércio internacional..$^{51}$

Nesse sentido, deve-se fazer uma leitura econômica das decisões dos atores privados no tocante à submissão de eventuais controvérsias à determinada jurisdição e regulação do direito material por determinada lei escolhida pelas partes. Em primeiro lugar, antes de se propor cláusulas de eleição de foro e lei aplicável às contrapartes, os atores privados fazem uma análise econômica dos riscos da jurisdição a que se está submetendo e se o contrato internacional a ser celebrado possui um custo-benefício válido. Após essa definição, incorporam-se ao contrato as cláusulas que cada parte encontra conforto, submetendo-as à negociação com a contraparte.

De forma genérica, a importância econômica da

o Direito Internacional dos Investimentos. In: ROSADO, Marilda (Org.). Direito Internacional dos Investimentos. Rio de Janeiro: Renovar, 2014. v. 1, p. 303-328. p. 303.

49 BERGER, Klaus Peter. Transnational Commercial Law in the Age of Globalization. In: SAGGI, CONFERENZE E SEMINARI 42, Disponível em: < http://cisgw3.law.pace.edu/cisg/biblio/berger1.html>. Acesso em 03 out. 2016. p. 2.

50 "A aplicabilidade do direito estrangeiro é vista como uma "armadilha da globalização", a divisão do mundo em diferentes sistemas jurídicos pode ser vista como uma barreira não tarifária" (tradução livre). BERGER, Klaus Peter. Transnational Commercial Law in the Age of Globalization. In: SAGGI, CONFERENZE E SEMINARI 42, Disponível em: < http:/ / cisgw3.law.pace.edu/cisg/ biblio/berger1.html>. Acesso em 03 out. 2016. p. 2.

51 BERGER, Klaus Peter. Transnational Commercial Law in the Age of Globalization. In: SAGGI, CONFERENZE E SEMINARI 42, Disponível em: < http://cisgw3.law.pace.edu/cisg/biblio/berger1.html>. Acesso em 03 out. 2016. p. 2. 
definição prévia de uma cláusula de eleição de foro se destaca no momento em que a controvérsia surge, isto porque

\begin{abstract}
Quando o litígio surge, há uma corrida para diversos locais como foros competentes, porque as partes procuram utilizar o tribunal do país em que sintam poder ser mais beneficiadas. Analisam as vantagens das regras relativas aos aspectos processuais da questão, da lei aplicável, dos custos para a contratação de advogados, entre outros. Essa busca é denominada forum shopping. ${ }^{52}$
\end{abstract}

A incerteza gerada pelo forum shopping pode afetar de forma direta os custos e as condições das transações "cross-border". É possível, ainda, afirmar que tal incerteza pode acarretar o desencorajamento de "certos negócios somente em razão da análise das condições dos tribunais com possibilidades de julgarem a questão". ${ }^{53}$

No tocante ao direito material, os princípios da Conferência da Haia sobre a escolha da lei aplicável em contratos internacionais consagram o entendimento sobre a importância da determinação das regras aplicáveis aos contratos com elementos de conexão com mais de um Estado. ${ }^{54}$ Nessa mesma linha, o Protocolo de Buenos Aires incluiu uma premissa em seu considerando, qual seja: "a necessidade de proporcionar ao setor privado dos Estados-Partes um quadro de segurança jurídica que garanta justas soluções e a harmonia internacional das decisões judiciais e arbitrais vinculadas à contratação no âmbito do Tratado de Assunção". ${ }^{5}$

Certeza, previsibilidade e segurança jurídica são fatores determinantes para as partes decidirem previamente a lei que desejam reger as disposições contratuais e prever as consequências jurídicas das suas escolhas. ${ }^{56}$

52 ARAUJO, Nádia; GAMA JUNIOR, Lauro; VARGAS, Daniela. Temas de Direito Internacional Privado no Projeto de Novo Código de Processo Civil. Revista de Arbitragem e Mediação, São Paulo, v. 28, n. 28, p. 147-158, jan./mar. 2011. p. 147.

53 ARAUJO, Nádia; GAMA JUNIOR, Lauro; VARGAS, Daniela. Temas de Direito Internacional Privado no Projeto de Novo Código de Processo Civil. Revista de Arbitragem e Mediação, São Paulo, v. 28, n. 28, p. 147-158, jan./mar. 2011. p. 148.

54 "When parties enter into a contract that has connections with more than one State, the question of which set of legal rules governs the transaction necessarily arises." HCCH. Convention of 30 June 2005 on Choice of Court Agreements. Disponível em: <https://www. hcch.net/en/instruments/conventions/full-text/?cid=98>. Acesso em: 04 out. 2016.

55 BRASIL. Protocolo de Buenos Aires sobre Jurisdição Internacional em Matéria Contratual. Disponível em: <http://www.camara.leg.br/ mercosul/Protocolos/BUENOS_AIRES.htm>. Acesso em: 04 out. 2016.

56 "Certainty and predictability are of particular importance in
Compreender as normas aplicáveis e como serão regidas as controvérsias oriundas da vertente contratual gera economia de recursos despendidos na recuperação dos créditos oriundos dos contratos internacionais de financiamento e alinha expectativas entre a área negocial e o jurídico das entidades financiadoras. A determinação da lei aplicável e consagração da autonomia da vontade são importantes não somente para o judiciário em solucionar a disputa, mas se configuram como sendo de maior relevância ainda para as partes envolvidas na transação. ${ }^{57}$

Estar na situação de negociar um contrato internacional e não saber quais os custos e consequências de litigá-lo em um tribunal que aplicará a lei obtida através da utilização do seu próprio método de DIPr certamente traz insegurança jurídica. Pode ser inclusive um fator de impedimento da contratação, pois os custos da incerteza podem não compensar as vantagens que seriam auferidas a partir da conclusão do contrato. ${ }^{58}$

Conclui-se que as partes devem agir com cautela e conhecimento da jurisdição e das leis que as negociações resultam por escolher aplicáveis à relação contratual. Não se trata de mera ocasião, mas sim de estratégia jurídica que pode gerar reflexos econômicos relevantes para quaisquer das partes. No âmbito dos contratos internacionais de financiamento, as cláusulas consagradas nos contratos internacionais são consideravelmente uniformizadas quando se trata de transações comerciais com relevante volume financeiro. Diante da particularidade dessas transações, parte-se para a análise específica desses contratos na próxima seção.

areas where the parties are likely to give advance thought to the legal consequences of their transactions." REESE, Willis. Conflict of Laws and the Restatement Second. 28 Law and Contemporary Problems. p. 679-699, 1963. Disponível em: < http://scholarship.law.duke. edu/lcp/vol28/iss4/2>. Acesso em: 04 out. 2016.

57 "The answer to this question is obviously important to a court or arbitral tribunal that must resolve a dispute between the parties but it is also important for the parties themselves, in planning the transaction and performing the contract, to know the set of rules that governs their obligations." HCCH. Convention of 30 June 2005 on Choice of Court Agreements. Disponível em: <https://www.hcch. net/en/instruments/conventions/full-text/?cid=98>. Acesso em: 04 out. 2016.

58 ARAUJO, Nadia de. Direito Internacional Privado: Teoria e Prática Brasileira. 6. ed. atual. e ampl. Porto Alegre: Revolução eBook, 2016. p. 735 . 


\section{O CASO DOS CONTRATOS INTERNACIONAIS DE FINANCIAMENTO: O CENTRO 'FINANCEIRO-JUDICIAL' DE Nova lorQue}

No âmbito dos contratos internacionais de financiamento, a lei de Nova Iorque é amplamente eleita como lei aplicável para reger as previsões contratuais. Do mesmo modo, os tribunais estaduais e federais de Nova Iorque são escolhidos, com frequência, como competentes para solução de controvérsias. Esse fenômeno ocorre tanto em negócios jurídicos bilaterais, quanto os multilaterais entre estrangeiros, sem qualquer elemento de conexão com o território norte-americano: $:^{59}$ as chamadas transações "cross-border". ${ }^{00}$

Nesse sentido, Nádia de Araújo corrobora o entendimento sobre como a escolha da lei aplicável de Nova Iorque se encontra presente nos contratos internacionais de financiamento:

\begin{abstract}
nos Estados Unidos, onde essas regras são de caráter estadual, a maioria dos contratos de financiamento contém cláusula elegendo a lei de Nova York como aplicável, já que a legislação desse estado sempre teve a preocupação de adequar-se às necessidades do comércio, transformando Nova York na capital dos negócios a partir da adoção de um aparato legislativo adequado. ${ }^{61}$
\end{abstract}

Esse fenômeno se evidencia pela própria uniformidade presentes nas cláusulas de 'jurisdiction' ${ }^{62} \mathrm{e}$ 'governing law ${ }^{93}$ dos contratos padronizados pelas associações privadas e amplamente utilizados pelos operadores do mercado financeiro internacional. Contratos internacionais de financiamento apresentam cláusulas de eleição de foro com competência (exclusiva ou não-exclusiva) ${ }^{64}$ para os tribunais de Nova Iorque, mesmo sem qualquer

59 "A dispute under a credit agreement with a non-U.S. borrower and a group of non-U.S. lenders could be heard in New York State courts even though there are "aliens" on both sides of the dispute". WIGHT, Richard; COOKE, Warren; GRAY, Richard. The LSTA's Complete Credit Agreement Guide. Nova York: McGraw Hill, 2009. p. 552. 60 A definição nesse termo encontra-se na nota de rodapé no. 3.

61 ARAUJO, Nadia de. Direito Internacional Privado: Teoria e Prática Brasileira. 6. ed. atual. e ampl. Porto Alegre: Revolução eBook, 2016. p. 735

62 Cláusula de eleição de foro (tradução livre).

63 Cláusula de lei aplicável (tradução livre).

64 'The submission is customarily 'nonexclusive;' the parties are, in other words, not forced to litigate in the selected jurisdiction [...]. This preserves for the lenders the right to sue the borrower in its home jurisdiction or elsewhere". WIGHT, Richard; COOKE, Warren; GRAY, Richard. The LSTA's Complete Credit Agreement Guide. Nova York: McGraw Hill, 2009. p. 552-553. elemento de conexão com este território.

A cláusula de eleição de foro ('submission to jurisdiction') dos contratos elaborados por associações privadas ${ }^{65}$ produzem instrumentos contratuais "tipo" para serem utilizados pelos operadores do mercado:

\begin{abstract}
the Borrower agrees that any action or proceeding with respect to this Agreement or any judgment entered by any court in respect thereof may be brought in the United States District Court for the Southern District of New York, in the Supreme Court of the State of New York sitting in New York County (including its Appellate Division), or in any other appellate court in the State of New York, as the party commencing such suit, action or proceeding may elect in its sole discretion" ${ }^{66}$
\end{abstract}

A cláusula de escolha da lei aplicável ('governing law'), por sua vez, dispõe: "This Agreement shall be construed in accordance with and governed by the law of the State of New York." ${ }^{67}$

O fundamento para essa escolha consubstancia-se no fato de Nova Iorque ter se consolidado como centro internacional financeiro e comercial. Assim, a legislação de Nova Iorque seria considerada pelos atores privados como mais sofisticada e capaz de solucionar casos predominantemente financeiros. ${ }^{68}$ Por outro lado, os tri-

65 Exemplos de associações privadas: Loan Market Association. Disponível em: <http://www.lma.eu.com/>. Acesso em 05 out. 2016. Assim como, The Loan Syndications and Trading Association Disponível em: <http://www.lsta.org/>. Acesso em 05 out. 2016.

66 "O devedor concordar que qualquer ação ou procedimento em relação a esse contrato ou qualquer julgamento iniciado por qualquer tribunal em relação ao mesmo pode ser levada ao Tribunal Distritual dos Estdos Unidos para o Distrito Sul de Nova Iorque na Suprema Corte do Estado de Nova Iorque no Condado de Nova Iorque (inclusive sua Divisão de Apelação) ou em qualquer outro tribunal de apelação do de Nova Iorque que a parte autora da ação ou procedimento venha a eleger a seu critério" (tradução livre). WIGHT, Richard; COOKE, Warren; GRAY, Richard. The LSTA's Complete Credit Agreement Guide. Nova York: McGraw Hill, 2009. p. 552.

67 "Esse contrato deverá ser regido de acordo com as leis do Estado de Nova Iorque" (tradução livre). WIGHT, Richard; COOKE, Warren; GRAY, Richard. The LSTA's Complete Credit Agreement Guide. Nova York: McGraw Hill, 2009. p. 548.

68 "Since New York is a leading center of international finance and commerce, parties to significant domestic and international commercial transactions widely regard New York law as a body of stable and reasonably sophisticated commercial law which might be appropriate to govern their arrangements and view the courts of New York or arbitration in New York as an appropriate forum for resolution of any disputes. However, the case law has left room for some differences of opinion concerning the extent to which such choices of law or choices of forum will be enforced in situations in which the transaction has little or no connection with New York." CARTER, James H. United States: New York Statute Amendments concerning reference to New York Law and New York Arbitration in international agreements. International Legal Materials, n. 24, p. 1019, 1985. Note que esse entendimento 
bunais de Nova Iorque teriam expertise para analisar a complexidade das cláusulas desses tipos de contratos, diferentemente de outros tribunais estrangeiros.

Ocorre que, nos Estados Unidos, diferentemente dos países de civil law, o método conflitual concede maior discricionariedade ao juiz ${ }^{69}$, sendo que a flexibilidade permitida no processo decisório do sistema conflitual norte-americano atual pode ensejar certa sensação de insegurança jurídica entre as partes. ${ }^{70}$

vigora desde 1984, momento em que foi codificado o Título 14 da Lei das Obrigações Gerais, modificando a doutrina do conflitos de leis que exigia, anteriormente, um elemento de conexão entre Nova York e o contrato. "On July 19, 1984, New York Governor Mario Cuomo signed into law Assembly Bill 7307-A,' codified primarily as title 14 of the New York Law of General Obligations. The new statute modifies New York's conflicts of law doctrine. Prior to title 14, New York courts generally enforced contracting parties' choice of New York. law to govern an agreement only if the state maintained a reason-able relationship with the agreement." RASHKOVER, Barry W. Title 14 New York Choice of Law Rule for Contractual Disputes: Avoiding the Unreasonable Results. Cornell Law Review, v. 71, p. 227-248, 1985. p. 227.

69 Apesar do sistema norte-americano se reger pelo mecanismo de "stare decisis", em que as decisões são fundamentadas a partir da vinculação ao precedente, instrumento este utilizando para conferir legitimidade, confiança e compliance às decisões judiciais, nota-se ainda se verificar o elemento da discricionariedade nas decisões judiciais figurando em paralelo ao mecanismo do "stare decisis". "Scholars (see Carter 1988; Dworkin 1978; Murphy, Fleming, and Barber 1995, 3033; Shapiro 1965) and jurists (Cardozo [1921] 1964; Wald 1995) recognize that judges continue to bave discretion even in the face of the norm of 'stare decisis'. For example, Supreme Court justices rarely decide two cases on the merits with precisely the same facts, and in many cases there may be conflicting precedent on an issue. Thus, there is often decisional leeway in determining whether a precedent governs a case (see Carter 1988; Schauer 1987)". No processo decisório de um caso concreto, os precedentes devem ser considerados e incorporados à fundamentação da decisão como instrumento para se consagrar fundamentos neutros, jurídicos e aumentar a sua legitimidade. Esse mecanismo, entretanto, ainda permite que se tenha certa discricionariedade nas decisões. HANSFORD, Thomas G.; SPRIGGS II, James F. The Politics of Precedent on the U.S. Supreme Court. Princeton: Princeton University Press, 2006. p. 22-23. O leitor deve observar, entretanto, que a discricionariedade mencionada trata da discricionariedade presente nas decisões do método conflitual norte-americano, existente mesmo após a chamada "revolução" no direito internacional privado norte-americano, conforme ressaltado por Symeon C. Symeonides. O autor faz uma crítica à flexibilidade resultante dessa revolução: "One of the consequences of these developments was an unprecedented degree of judicial flexibility in choiceof-law decisions. To be sure, flexibility is preferable to uncritical rigidity, but too much flexibility can be as bad as no flexibility at all. When each case is decided ad hoc as if it were a case of first impression, multiple problems arise, including increased litigation costs, waste of judicial resources, and an increased danger of judicial subjectivism, which has been aptly described as 'judicial particularistic intuitionism' or 'impressionnisme juridique". SYMEONIDES, Symeon C. The American choice-of-law revolution in the courts: today and tomorrow. Recueil des Cours de la Académie de Droit International, tome 35, p. 418-418, 2002.

70 "O incremento da discricionariedade tende a reduzir a segurança e a previsibilidade das decisões e a permitir maior exercício de
"No sistema americano, a questão deve ser vista a partir de seu resultado, sendo a seleção feita de acordo com o conteúdo do problema em questão, procurando-se a melhor norma material para solucioná-lo". ${ }^{71}$ Além da particularidade e flexibilidade da solução conflitual a cada caso, deve-se acrescentar, ainda, que o sistema norte-americano é híbrido, pois "evoluiria conforme o common law", no tocante às decisões casuísticas, mas estaria limitado aos dispositivos constitucionais "típicos do civil law". ${ }^{72}$

Para determinar a competência de um Estado norte-americano para julgar uma ação, deve-se considerar dois critérios: "subject-matter" e "personal jurisdiction". ${ }^{73}$ Enquanto que a "subject-matter" encontra-se baseada na competência em razão da matéria e de reduzida possibilidade de alteração, a jurisdição pessoal consolida-se no fato de que "a jurisdição de uma corte in personam fundava-se num poder de fato sobre a pessoa" ${ }^{74}$ tornando possível que as partes criem jurisdição pessoal no contrato. Nesse sentido, José Maria Tesheiner esclarece:

Trata-se de determinar o Estado-membro em que pode ser proposta uma ação, seja na Justiça do próprio Estado, ou na Justiça Federal ou, em outras palavras, de determinar, de conformidade com a Constituição, qual Estado-membro tem jurisdição no caso concreto. A jurisdição pode ser geral (por

concretude por aquele que deveria apenas aplicar o direito posto". VASCONCELOS, Raphael. Premissas Fundamentais do Direito Internacional Privado. In: TIBURCIO, Carmen; MENEZES, Wagner; VASCONCELOS, Raphael (Org.). Panorama do Direito Internacional Privado Atual e outros Temas Contemporâneos. Belo Horizonte: Arraes Editores, 2015. p. 39-40.

71 ARAUJO, Nadia de. Direito Internacional Privado: Teoria e Prática Brasileira. 6. ed. atual. e ampl. Porto Alegre: Revolução eBook, 2016. p. 106.

72 VASCONCELOS, Raphael. Premissas Fundamentais do Direito Internacional Privado. In: TIBURCIO, Carmen; MENEZES, Wagner; VASCONCELOS, Raphael (Org.). Panorama do Direito Internacional Privado Atual e outros Temas Contemporaneos. Belo Horizonte: Arraes Editores, 2015. p. 44.

73 Trata-se da competência em razão da matéria, como esclarece os autores "subject-matter jurisdiction refers to the power of a particular court to bear a particular kind of case". Enquanto que "personal jurisdiction" é aquela competência em razão da pessoa "Personal jurisdiction refers to the power of a court over a particular entity". Como a jurisdição em razão da material não pode ser criada por contrato entre as partes, WIGHT, Richard; COOKE, Warren; GRAY, Richard. The LSTA's Complete Credit Agreement Guide. Nova York: McGraw Hill, 2009. p. 551.

74 Artigo 12 (b)(2) do Código de Processo Civil Federal: "personal jurisdiction is the power of a court to exercise control over a particular person or item of property". TESHEINER, José Maria. Jurisdição territorial nos Estados Unidos da América do Norte e Competência Internacional e de Foro no Brasil. Revista Eletrônica de Direito Processual, Rio de Janeiro, v. 13, p. 259-274, 2014. p. 265. 
exemplo, qualquer causa contra réu domiciliado no Estado) ou específica (por exemplo, causa derivada de ato ilícito praticado pelo réu no território do Estado). ${ }^{75}$

Para que as partes possam criar jurisdição pessoal no contrato, é preciso que exista uma "base" para a jurisdição e que o réu tenha sido notificado. O critério de "base" funda-se na declaração das partes em consentirem na submissão, no âmbito do contrato, à jurisdição escolhida. Por essa razão que os contratos internacionais de financiamento estabelecem cláusulas de eleição de foro com competência (exclusiva ou não-exclusiva) para os tribunais de Nova Iorque, ${ }^{76}$ declarando as partes que consentem com a jurisdição eleita.

Destaca-se, ainda, que para determinar se a jurisdição do Estado é competente ou não, a jurisprudência norte-americana estabeleceu alguns critérios segundo o regramento da jurisdição pessoal. O primeiro deles "minimum contacts with forum", foi estabelecido no âmbito da decisão International Shoe Co. v. Washington 77 de 1945. Nesse julgado, derrogou-se a concepção histórica de que o requisito para exercício da jurisdição in personam era "presença [do réu] no território sob jurisdição da corte", ${ }^{78}$ ampliando-se o escopo da jurisdição pessoal para a concepção de que bastaria que o réu tivesse contatos mínimos ("minimum contacts") com o tribunal para este se considerar competente. A verificação dos contatos mínimos se consolida através do contato sistemático e contínuo do réu com o território do Estado. Outro teste seria o "long Arm jurisdiction with forum state", critério que determina que, para o tribunal exercer "personal jurisdiction" sobre um réu, deverá existir um regulamento que permita que o tribunal explicitamente o autorize a

75 TESHEINER, José Maria. Jurisdição territorial nos Estados Unidos da América do Norte e Competência Internacional e de Foro no Brasil. Revista Eletrônica de Direito Processual, Rio de Janeiro, v. 13, p. 259-274, 2014. p. 260.

76 "New York's dominant thrust bas been in the area of finance contracts.". Os autores fazem apresentam um série de resultados empíricos que evidenciam que as partes de contratos financeiros preferem as leis de Nova Iorque e a eleição de foro para esse Estado. EISENBERG, Theodore; MILLER, Geoffrey. The Flight to New York: An Empirical Study of Choice of Law and Choice of Forum Clauses in Publicly-Held Companies' Contracts. New York University Law and Economics Working Papers, Paper 124, p. 1-42, 2008. p. 21.

77 Cornell University Law School. International Shoe v. State of Washington. 326 U.S. 310. Disponível: <https://www.law.cornell. edu/supremecourt/text/326/310>. Acesso em: 05 out. 2016.

78 TESHEINER, José Maria. Jurisdição territorial nos Estados Unidos da América do Norte e Competência Internacional e de Foro no Brasil. Revista Eletrônica de Direito Processual, Rio de Janeiro, v. 13, p. 259-274, 2014. p. 265. exercer tal jurisdição. ${ }^{79}$

Para que a escolha da lei pelas partes seja considerada válida e o tribunal considerado competente, estabeleceu-se um teste da relação razoável com a transação ("reasonable relation") ${ }^{80}$ e violação da ordem pública. Caso não houvesse relação mínima ou caso se caracterizasse a violação da ordem pública, os tribunais de Nova Iorque tendiam a não considerar válida a escolha da lei aplicável. ${ }^{81} \mathrm{Na}$ realidade, o requisito do "reasonable relation" 82 é facilmente preenchido com o consentimento das partes em aplicar as leis de Nova Iorque e em submeter o seu litígio a esse foro. ${ }^{83}$ Quanto à ordem pública, este argumento dificilmente é considerado, pois o pressuposto principal considerado para o Estado de Nova Iorque se consagrar como centro financeiro comercial é respeitar a autonomia da vontade das partes. ${ }^{84}$

Como nos Estados Unidos a discricionariedade do método conflitual do juiz é latente ${ }^{85} \mathrm{e}$ as decisões sobre

79 No caso dos contratos internacionais de financiamento, esse regramento está previsto no "General Obligations Law" (GOL) editado pelo Estado de Nova Iorque.

80 No âmbito contratual, section 187 do Restatement (Second) of Conflicts of Law prevê "the chosen state has no substantial relationship to the parties or the transaction and there is no other reasonable basis for the parties' choice". U.S. Restatement (Second) of Conflicts of Law. Disponível em: <http://www.kentlaw.edu/perritt/conflicts/rest187. html>. Acesso em 05 out. 2016.

81 "The chosen law had to have a reasonable relationship with the contract itself.”. EISENBERG, Theodore; MILLER, Geoffrey. The Flight to New York: An Empirical Study of Choice of Law and Choice of Forum Clauses in Publicly-Held Companies' Contracts. New York University Law and Economics Working Papers, Paper 124, p. 1-42, 2008. p. 10 .

82 Esse critério não é bem definido, mas alguns parâmetros podem guiar os contraentes para considerar que essa relação existe, são eles: (i) quando o desembolso do financiamento ocorrer no território norte-americano, (ii) o pagamento ser realizado nos Estados Unidos e (iii) o credor se encontrar domiciliado neste território. WIGHT, Richard; COOKE, Warren; GRAY, Richard. The LSTA's Complete Credit Agreement Guide. Nova York: McGraw Hill, 2009. p. 549.

83 "A contract may bear a reasonable relationship to New York merely because of the parties' decision to select New York law". EISENBERG, Theodore; MILLER, Geoffrey. The Flight to New York: An Empirical Study of Choice of Law and Choice of Forum Clauses in Publicly-Held Companies' Contracts. New York University Law and Economics Working Papers, Paper 124, p. 1-42, 2008. p. 12.

84 EISENBERG, Theodore; MILLER, Geoffrey. The Market for Contracts. New York University, Law \& Economics Research Paper, n. 06-45, p. 1-49, 2007. p. 34.

85 Como mencionado na nota de rodapé n. 69, um dos resultados da revolução do direito internacional privado norte-americano citada por Symeon Symeonides foi a flexibilidade judicial nas decisões no âmbito do método conflitual norte-americano. SYMEONIDES, Symeon C. The American choice-of-law revolution in the courts: 
escolha da lei aplicável e eleição de foro são decididas de forma casuística, ${ }^{86}$ os celebrantes de contratos internacionais de financiamento poderiam acabar por se sentir inseguros quanto ao exercício da autonomia da vontade, visto os diversos critérios utilizados pela jurisprudência.

Essa premissa, no entanto, foi sendo desconstruída pelas alterações legislativas em 1984 e pelos precedentes dos tribunais de Nova Iorque voltados para esse tema, que tem fortemente assegurado aos contratantes que a escolha da lei aplicável e eleição de foro serão respeitadas. ${ }^{87}$ Houve, assim, um esforço programado das autoridades públicas em construir uma imagem de Nova Iorque como centro 'financeiro-judicial' dos contratos internacionais. ${ }^{88}$

\section{Nesse sentido, Eisenberg e Miller destacam:}

The upshot of these intertwining provisions is that parties to major commercial contracts received a guarantee that New York courts will respect clauses selecting New York as the law or forum, regardless of whether the parties have any other connections with New York State. ${ }^{89}$

Assim, em 1984 foram editados os artigos 5-1401 e 5-1402 da "General Obligations Law" (GOL). ${ }^{90}$ A regra

today and tomorrow. Recueil des Cours de la Académie de Droit International, tome 35, p. 417-418, 2002.

86 "because they are not legislative in nature, and because they technically admit the possibility of exceptions, New York case law does not provide absolute assurance to attorneys drafting major commercial contracts." EISENBERG, Theodore; MILLER, Geoffrey. The Market for Contracts. New York University, Law \& Economics Research Paper, n. 06-45, p. 1-49, 2007. p. 37.

87 Os autores defendem que existe uma corrida estimulada pelo próprio Estado de Nova Iorque para atrair a aplicação das suas leis e eleição de foro. EISENBERG, Theodore; MILLER, Geoffrey. The Market for Contracts. New York University, Law \& Economics Research Paper, n. 06-45, p. 1-49, 2007. p. 33.

88 "New York and other states compete for litigation and forum selection clauses by offering attractive judicial services to major commercial parties". EISENBERG, Theodore; MILLER, Geoffrey. The Flight to New York: An Empirical Study of Choice of Law and Choice of Forum Clauses in Publicly-Held Companies' Contracts. New York University Law and Economics Working Papers, Paper 124, p. 1-42, 2008. p. 13.

89 "O resultado dessas previsões interligadas consubstancia no fato de que as partes dos principais contratos comerciais recebem uma garantia de que os tribunais de Nova Iorque vão respeitar as cláusulas que selecionam Nova Iorque como foro e como lei aplicável, independentemente se as partes possuem ou não qualuqer conexão com o Estado de Nova Iorque". (tradução livre). EISENBERG, Theodore; MILLER, Geoffrey. The Market for Contracts. New York University, Law \& Economics Research Paper, n. 06-45, p. 1-49, 2007. p. 39.

90 US NY COURTS. IRB-Brasil Resseguros, S.A. v. Inepar Investments, S.A. Opinion of Chief Juge, Lippman, p. 1-8, 2012. Disponível em: <http://www.nycourts.gov/ctapps/Decisions/2012/ do artigo 5-140191 da GOL permite a escolha da lei aplicável e eleição de foro de Nova Iorque pelas partes, independentemente do cumprimento do critério "reasonable relation", no caso de contratos comerciais com valor igual ou maior de 250 mil dólares. ${ }^{92}$ A regra do artigo 5-1402 $2^{93}$ permite a eleição de foro em contratos em que houve escolha de lei aplicável nos termos do artigo 5-1401 da GOL, cujo montante da obrigação seja igual ou maior que 1 milhão de dólares e tenha uma cláusula de eleição de foro, em que a empresa estrangeira ou não-residente concorda em submeter eventual controvérsia à jurisdição dos tribunais de Nova Iorque.

Desse modo, os critérios que devem ser observados para que a escolha das partes seja considerada válida

Dec12/191opn12.pdf>. Acesso em: 03 out. 2016. p. 4-5.

91 "N.Y. GOB. LAW \5-1401: "Choice of law 1. The parties to any contract, agreement or undertaking, contingent or otherwise, in consideration of, or relating to any obligation arising out of a transaction covering in the aggregate not less than two hundred fifty thousand dollars, including a transaction otherwise covered by subsection one of section 1-105 of the uniform commercial code, may agree that the law of this state shall govern their rights and duties in whole or in part, whether or not such contract, agreement or undertaking bears a reasonable relation to this state. This section shall not apply to any contract, agreement or undertaking (a) for labor or personal services, (b) relating to any transaction for personal, family or household services, or (c) to the extent provided to the contrary in subsection two of section 1-105 of the uniform commercial code. 2. Nothing contained in this section shall be construed to limit or deny the enforcement of any provision respecting choice of law in any other contract, agreement or undertaking". FINDLAW. New York General Obligations Law \5-1401. Choice of law. Disponível em: <http://codes.findlaw.com/ny/general-obligations-law/gobsect-5-1401.html>. Acesso em: 03 out. 2016.

92 WIGHT, Richard; COOKE, Warren; GRAY, Richard. The LSTA's Complete Credit Agreement Guide. McGraw Hill, 2009, p. 549. 93 "N.Y. GOB. LAW \ 5-1402: 1. Notwithstanding any act which limits or affects the right of a person to maintain an action or proceeding, including, but not limited to, paragraph (b) of section thirteen hundred fourteen of the business corporation law and subdivision two of section two hundred-b of the banking law, any person may maintain an action or proceeding against a foreign corporation, non-resident, or foreign state where the action or proceeding arises out of or relates to any contract, agreement or undertaking for which a choice of New York law has been made in whole or in part pursuant to section 5-1401 and which (a) is a contract, agreement or undertaking, contingent or otherwise, in consideration of, or relating to any obligation arising out of a transaction covering in the aggregate, not less than one million dollars, and (b) which contains a provision or provisions whereby such foreign corporation or non-resident agrees to submit to the jurisdiction of the courts of this state. 2. Nothing contained in this section shall be construed to affect the enforcement of any provision respecting choice of forum in any other contract, agreement or undertaking." FINDLAW. New York General Obligations Law $\int 5-1402$. Choice of forum. Disponível em: <http://codes.lp.findlaw.com/nycode/GOB/5/14/5-1402 sthash.j4njByf7.dpuf>. Acesso em: 03 out. 2016. 
nos contratos comerciais internacionais se consolidaram de forma objetiva. ${ }^{94}$ Esses critérios são (i) transação no montante igual ou maior que 1 milhão de dólares; (ii) as partes devem ter concordado em submeter eventual controvérsia à jurisdição dos tribunais de Nova Iorque e; (iii) escolha da lei de Nova Iorque como aplicável de acordo com o critério do artigo 5-1401 da GOL. ${ }^{95}$

Estabeleceu-se, também, a proibição aos tribunais de Nova Iorque em negar competência com base no forum non conveniens, quando a ação fundar-se em contrato com eleição de foro baseado no artigo 5-1402 da GOL e leis aplicáveis de Nova Iorque. ${ }^{96}$ Em 1995, criou-se um departamento comercial permanente na Suprema Corte, ${ }^{97}$ altamente especializado para lidar com as controvérsias comerciais de alta complexidade.

$\mathrm{Na}$ espreita de se consolidar como um centro 'financeiro-judicial', os tribunais de Nova Iorque presumem que a autonomia da vontade deverá prevalecer quanto à escolha da lei aplicável.

Esse entendimento foi consagrado no julgamento IRB-Brasil Resseguros, S.A. v. Inepar Investments, S.A., envolvendo o tema da escolha da lei aplicável e eleição de foro. O julgado teve por objeto um contrato, no qual os contraentes consentiram em eleger o foro de Nova Iorque. Além disso, as partes escolheram aplicar as leis de Nova Iorque, porém não incluíram a expressão "without regard to conflict of laws principles' $\$ 8$ na cláusula de 'governing law'. O tribunal de Nova Iorque entendeu que "express

94 Ressalta-se que "in the tort and antitrust context, the ability to access the New York courts is not so clear". KUCK, Lea; HELLMANN, Betsy. International Cases Court of Appeals Decided in 2012, Looking Ahead to 2013. New York Law Journal, v. 49, n. 46, p. 1-3, 2013. p. 2. 95 US NY COURTS. IRB-Brasil Resseguros, S.A. v. Inepar Investments, S.A. Opinion of Chief Juge, Lippman, p. 1-8, 2012. Disponível em: <http://www.nycourts.gov/ctapps/Decisions/2012/ Dec12/191opn12.pdf $>$. Acesso em: 03 out. 2016. p. 6.

96 EISENBERG, Theodore; MILLER, Geoffrey. The Market for Contracts. New York University, Law \& Economics Research Paper, n. 06-45, p. 1-49, 2007. p. 39.

97 "The bad repute of the New York state court system posed an obvious threat to New York's ability to compete for contracts [...] In 1993 the state instituted a pilot commercial court program in the New York County (Manhattan) Supreme Court (...)the state established a permanent Commercial Division of the Supreme Court in 1995”. EISENBERG, Theodore; MILLER, Geoffrey. The Market for Contracts. New York University, Law \& Economics Research Paper, n. 06-45, p. 1-49, 2007. p. 41; 42.

98 "sem observar os princípios de conflitos de leis" (tradução livre). US NY COURTS. IRB-Brasil Resseguros, S.A. v. Inepar Investments, S.A. Opinion of Chief Juge, Lippman, p. 1-8, 2012. Disponível em: <http://www.nycourts.gov/ctapps/Decisions/2012/ Dec12/191opn12.pdf>. Acesso em: 03 out. 2016. p. 2. contract language excluding New York's conflict-of-laws principles is not necessary", "99 uma vez que as partes expressaram claramente seu intuito em aplicar as leis de Nova Iorque.

No voto do Chief Juge Lippman na decisão IRB-Brasil Resseguros, S.A. v. Inepar Investments, S.A., evidencia-se o fundamento para consagrar a autonomia da vontade nos termos do histórico desenvolvimento legislativo e jurisprudencial nova-iorquino:

The Legislature passed the statute in 1984 in order to allow parties without New York contacts to choose New York law to govern their contracts. Prior to the enactment of $\int 5-1401$, the Legislature feared that New York courts would not recognize "a choice of New York law [in certain contracts] on the ground that the particular contract had insufficient 'contact' or 'relationship' with New York" (Sponsor's Mem, Bill Jacket, L 1984, ch 421). Instead of applying New York law, the courts would conduct a conflicts analysis and apply the law of the jurisdiction with "'the most significant relationship to the transaction and the parties [...] As a result, parties would be deterred from choosing the law of New York in their contracts, and the Legislature was concerned about how that would affect the standing of New York as a commercial and financial center". ${ }^{100}$

Importante esclarecer, por fim, que no âmbito dos contratos de financiamento, a escolha das partes se volta para Nova Iorque, pois o seu aparato normativo se

99 "linguagem contratual expressa excluindo os princípios de conflitos de leis não é necessária" (tradução livre.) Além disso, o julgado corroborou "To find here that courts must engage in a conflict-of-law analysis despite the parties' plainly expressed desire to apply New York. law would frustrate the Legislature's purpose of encouraging a predictable contractual choice of New York commercial law and, crucially, of eliminating uncertainty regarding the governing law." US NY COURTS. IRB-Brasil Resseguros, S.A. v. Inepar Investments, S.A. Opinion of Chief Juge, Lippman, p. 1-8, 2012. Disponível em: <http://www.nycourts.gov/ctapps/Decisions/2012/Dec12/191opn12.pdf>. Acesso em: 03 out. 2016. p. 7. 100 "O poder legislativo editou o estatuto em 1984 com objetivo de permitir às partes sem contato com Nova Iorque que escolhessem as leis de Nova Iorque para reger seus contratos. Antes da edição do artigo 5-1401, o poder legislativo temia que os tribunais de Nova Iorque não reconheceriam "a escolha da Lei de Nova Iorque como aplicável em certos contratos com fundamento no fato de que um contrato particular não teria suficiente contato ou relação com Nova Iorque". Ao invés de se aplicar a lei de Nova Iorque, os tribunais iriam conduzir uma análise de conflitos de lei e aplicar a lei da jurisdição que tivesse a relação mais substancial com a transação e com as partes [...]. Como resultado, as partes iriam se dissuadir de escolher as lei de Nova Iorque em seus contratos. Assim, o poder legislativo se preocupou sobre como esse fenômeno iria afetar a posição de Nova Iorque como um centro financeiro e comercial" (tradução livre). US NY COURTS. IRB-Brasil Resseguros, S.A. v. Inepar Investments, S.A. Opinion of Chief Juge, Lippman, p. 1-8, 2012. Disponível em: <http://www.nycourts.gov/ctapps/Decisions/2012/Dec12/191opn12.pdf>. Acesso em: 03 out. 2016. p. 4-5. 
consagra como sendo o preferido entre os atores privados para reger esses tipos de contrato, cuja aplicação é especialmente requerida pelos credores. ${ }^{101}$ "New York commercial law is relatively extensive, stable, and "creditor-frien$d y$," and this fact, coupled with Section 5-1401 of the General Obligations Law, makes it favored choice as the governing law for credit agreements". ${ }^{102}$ Até porque, a escolha equivocada do foro para dirimir eventuais controvérsias contratuais de financiamento pode gerar prejuízos financeiros de grande monta para o credor. ${ }^{103}$ Assim, a regulamentação dos artigos 5-1401 e 5-1402 da GOL, a proibição de se aplicar a doutrina do forum non conveniens e os precedentes consagrados, como o IRB-Brasil Resseguros, S.A. v. Inepar Investments, S.A., trouxeram conforto para as partes estrangeiras nesses tipos contratuais. Esses 'instrumentos' foram sendo amplamente utilizados pelos juristas como forma de demonstrar a segurança que os tribunais de Nova Iorque tem buscado conceder aos atores privados como forma de atração de uma gama de contratos comerciais e partes sofisticadas para seus foros de competência.

Os esforços do Estado de Nova Iorque realizados através de mecanismos legislativos e judiciais resultaram em um fenômeno de clara preferência pela escolha dos atores privados nas negociações contratuais. Em uma pesquisa realizada em 2002 pelos autores Eisenberg e Miller, ${ }^{104}$ verificou-se que dos 2.865 contratos comer-

101 Deve-se ressaltar que não é recomendável escolher a lei onde se situa o devedor como lei aplicável. Esse tipo de escolha pode se tornar um risco por algumas razões: dificuldade em se compreender o ordenamento jurídico aplicável, além da hipótese de ser contra as políticas internas do credor. WIGHT, Richard; COOKE, Warren; GRAY, Richard. The LSTA's Complete Credit Agreement Guide. Nova York: McGraw Hill, 2009. p. 549.

102 "o direito empresarial de Nova Iorque é relativamente extenso, estável e favorável ao credor e esse fato, juntamente com o artigo 5-1401 da Lei geral de obrigações, faz com que seja a escolha preferida como lei aplicável nos contratos de crédito" (tradução livre). WIGHT, Richard; COOKE, Warren; GRAY, Richard. The LSTA's Complete Credit Agreement Guide. Nova York: McGraw Hill, 2009. p. 549.

103 Deve-se ficar muito atento para os prejuízos de se eleger uma jurisdição estrangeira para o caso vertente: "Commeencing litigation in the borrower's jurisdiction can entail incremental travel and other expenses, be less certain of a proper outcome, and, of course, eat up more loan officer time". Além disso, deve-se levar em consideração "the possibility that a local court would favor a local company and perhaps misconstrue New York law". WIGHT, Richard; COOKE, Warren; GRAY, Richard. The LSTA's Complete Credit Agreement Guide. Nova York: McGraw Hill, 2009. p. 551.

104 EISENBERG, Theodore; MILLER, Geoffrey. The Flight to New York: An Empirical Study of Choice of Law and Choice of Forum Clauses in Publicly-Held Companies' Contracts. New York ciais analisados, $46 \%$ dos contratos continham escolha da lei aplicável para Nova York. ${ }^{105}$ A grande maioria dos contratos eram financeiros, incluindo os financiamentos: "New York's dominant thrust has been in the area of finance contracts", ${ }^{106}$ fator este resultante em um alto número de instituições financeiras no território deste Estado. Para a eleição do foro, identificou-se o padrão da escolha da lei aplicável como parâmetro. Assim, o foro eleito usualmente é aquele, cuja lei foi escolhida para se aplicar ao contrato. Portanto, para os contratos que designavam as leis de Nova Iorque como aplicáveis, 95\% elegiam o foro de Nova Iorque como competente. ${ }^{107}$

\section{Considerações Finais}

Neste trabalho, buscou-se fazer uma análise sobre os aspectos relevantes do exercício da autonomia da vontade na escolha da lei aplicável e eleição de foro nos contratos internacionais de financiamento. Por um lado, foram abordadas questões controversas no âmbito do ordenamento jurídico brasileiro para ressaltar as discussões colocadas pela doutrina, a inconsistência das decisões judiciais e alterações legislativas editadas com objetivo de solucionar a controvérsia. Muito se aclamou pela consagração do exercício da autonomia da vontade no direito brasileiro à luz dos exemplos dos ordenamentos jurídicos estrangeiros.

Em segundo lugar, procurou-se evidenciar a visão econômica que os atores privados adotam no momento da escolha da lei aplicável e eleição de foro nos contratos internacionais. Medida esta que evidencia a importância de uma discussão sobre a possibilidade do exercício da

University Law and Economics Working Papers, Paper 124, p. 1-42, 2008. p. 16-.

105 EISENBERG, Theodore; MILLER, Geoffrey. The Flight to New York: An Empirical Study of Choice of Law and Choice of Forum Clauses in Publicly-Held Companies' Contracts. New York University Law and Economics Working Papers, Paper 124, p. 1-42, 2008. p. 19.

106 "o impulso dominante de Nova Iorque tem sido na área de contratos" (tradução livre). EISENBERG, Theodore; MILLER, Geoffrey. The Flight to New York: An Empirical Study of Choice of Law and Choice of Forum Clauses in Publicly-Held Companies' Contracts. New York University Law and Economics Working Papers, Paper 124, p. 1-42, 2008. p. 21.

107 EISENBERG, Theodore; MILLER, Geoffrey. The Flight to New York: An Empirical Study of Choice of Law and Choice of Forum Clauses in Publicly-Held Companies' Contracts. New York University Law and Economics Working Papers, Paper 124, p. 1-42, 2008. p. 35. 
autonomia da vontade. Os fundamentos econômicos se demonstraram capazes de reverberar a necessidade de se permitir que os atores privados tenham liberdade na negociação contratual e escolham a lei que mais lhe favorecem e o tribunal mais conveniente para julgar suas controvérsias contratuais.

O fenômeno que ocorre no âmbito dos contratos internacionais de financiamento demonstra que a prática contratual está permeada pela autonomia da vontade. Trata-se de um desejo claro de se escolher o centro financeiro internacional - Nova Iorque - para solucionar as controvérsias dos financiamentos. Essa decisão não se resume aos contraentes norte-americanos, mas incontáveis partes estrangeiras que desejam se beneficiar do arcabouço jurídico sofisticado e expertise desses juízes para dirimir os seus conflitos financeiros sem qualquer contato com os Estados-Unidos.

Dessa forma, decidiu-se por esclarecer como o sistema norte-americano conduz o mecanismo de escolha de lei aplicável e eleição de foro no âmbito dos financiamentos. Demonstrou-se que o Estado de Nova Iorque promoveu uma verdadeira corrida para atração dos contratos comerciais. Ao longo dos anos, deixou-se para trás a incredulidade de que a escolha das partes seria consagrada e o problema jurídico que a desconsideração da autonomia da vontade causaria para os atores privados, a fim de se consagrar o posicionamento de que dificilmente se derrogaria a eleição de foro e escolha da lei de Nova Iorque pelos atores privados, mesmo sem qualquer relação razoável com o território deste Estado norte-americano.

Portanto, consagrou-se a autonomia da vontade nos tribunais de Nova Iorque. Esse posicionamento passou por uma evolução histórica, mudança de paradigma nesses tribunais, já que não se estabeleceu dessa forma desde o início. O caso de Nova Iorque pode servir, portanto, como exemplo para o sistema jurídico brasileiro e outros ordenamentos jurídicos. Exemplo para um mecanismo que pode atrair recursos financeiros e permitir segurança jurídica às partes que eventualmente venham ao território local de um país com objetivo de contratar e, eventualmente, litigar. A segurança jurídica só tende a trazer resultados benéficos, especialmente, a atração de um volume maior de investimento estrangeiro para o país.

\section{REFERÊNCIAS}

ARAUJO, Nadia de. A necessária mudança do artigo 9o da LINDB: o avanço que faltava para a consagração da autonomia da vontade no DIPr brasileiro. In: RAMOS, André de Carvalho (Org.). Direito Internacional Privado: Questões Controvertidas. Belo Horizonte: Arraes Editores, 2015. p. 289-309.

ARAUJO, Nadia de. Contratos Internacionais e a jurisprudência brasileira: Lei aplicável, ordem pública e cláusula de eleição de foro. In: RODAS, João Grandino (Coord.). Contratos Internacionais. 3. ed. rev. atual. e ampl. São Paulo: Revista dos Tribunais, 2002. p. 202-208.

ARAUJO, Nadia de. Direito Internacional Privado: Teoria e Prática Brasileira. 6. ed. atual. e ampl. Porto Alegre: Revolução eBook, 2016.

ARAUJO, Nádia; GAMA JUNIOR, Lauro; VARGAS, Daniela. Temas de Direito Internacional Privado no Projeto de Novo Código de Processo Civil. Revista de Arbitragem e Mediação, São Paulo, v. 28, n. 28, p. 147-158, jan./mar. 2011.

ARAUJO, Nadia; SPTIZ, Lidia; NORONHA, Carolina. $\mathrm{O}$ novo $\mathrm{CPC}$ nas relações internacionais. Jornal Valor Econômico, 13 de jan. de 2015. Disponível em: <http://www.valor.com.br/legislacao/3856442/onovo-cpc-nas-relacoes-internacionais $>$. Acesso em 04 out. 2016.

BAPTISTA, Luiz Olavo. Dos contratos internacionais: uma visão teórica e prática. São Paulo: Saraiva, 1994.

BARRETTO, Vincente de Paulo. Globalização, direito cosmopolítico e direitos humanos. In: DIREITO, Carlos Alberto Menezes; TRINDADE, Antônio Augusto Cançado; PEREIRA, Antônio Celso Alves. Novas perspectivas do direito internacional contemporâneo: Estudos em homenagem ao Professor Celso D. de Albuquerque Mello. Rio de Janeiro: Renovar, 2008.

BERGER, Klaus Peter. Transnational Commercial Law in the Age of Globalization. In: SAGGI, CONFERENZE E SEMINARI 42, Disponível em: <http:// cisgw3.law.pace.edu/cisg/biblio/berger1.html>. Acesso em 03 out. 2016.

BRASIL. Decreto-Lei no 4.657, 4 de Setembro de 1942 (Redação dada pela Lei no 12.376 , de 2010). Disponível em: <http://www.planalto.gov.br/ccivil_03/decreto-lei/ Del4657compilado.htm>. Acesso em 04 out. 2016. 
BRASIL. Lei $n^{0}$ 3.071, de $1^{\circ}$ de janeiro de 1916. Disponível em: <http://www.planalto.gov.br/ccivil_03/leis/ L3071.htm>. Acesso em 03 out 2016.

BRASIL. Projeto de Lei no 281 de 2012. Disponível em: <http://www.senado.leg.br/atividade/rotinas/materia/getPDF.asp?t=182349\&tp=1>. Acesso em: 04 out. 2016.

BRASIL. Protocolo de Buenos Aires sobre Jurisdição Internacional em Matéria Contratual. Disponível em: <http://www. camara.leg.br/mercosul/Protocolos/BUENOS_AIRES.htm>. Acesso em: 04 out. 2016.

CARTER, James H. United States: New York Statute Amendments concerning reference to New York Law and New York Arbitration in international agreements. International Legal Materials, n. 24, 1985.

CASTRO, Joana Holzmeister. Cláusula de Eleição de Foro em Contratos Internacionais: o que muda com o novo Código de Processo Civil. 2015. 57 f. Monografia (Graduação em Direito) - Faculdade de Direito, Pontifícia Universidade Católica do Rio de Janeiro, Rio de Janeiro, 2005.

CORNELL UNIVERSITY LAW SCHOOL. International Shoe v. State of Washington. 326 U.S. 310. Disponível: <https://www.law.cornell.edu/supremecourt/ text/326/310>. Acesso em: 05 out. 2016.

DOLINGER, Jacob; TIBURCIO, Carmen. Direito Internacional Privado: Parte Geral e Processo Internacional. 12. ed. rev. atual. e ampl. Rio de Janeiro: Forense, 2016.

EISENBERG, Theodore; MILLER, Geoffrey. The Flight to New York: An Empirical Study of Choice of Law and Choice of Forum Clauses in Publicly-Held Companies' Contracts. New York University Law and Economics Working Papers, Paper 124, p. 1-42, 2008.

EISENBERG, Theodore; MILLER, Geoffrey. The Market for Contracts. New York University, Law \& Economics Research Paper, n. 06-45, p. 1-49, 2007.

FINDLAW. New York General Obligations Law \5-1401. Choice of law. Disponível em: <http://codes.findlaw. com/ny/general-obligations-law/gob-sect-5-1401. html>. Acesso em: 03 out. 2016.

FINDLAW. New York General Obligations Law \5-1402. Choice of forum. Disponível em: <http://codes. lp.findlaw.com/nycode/GOB/5/14/5-1402 - sthash. j4njByf7.dpuf>. Acesso em: 03 out. 2016.
FRANÇA. Code de Procédure Civile. <https://www.legifrance.gouv.fr $/$ affichCode.do;jsessionid=0F2723F5201 803CF911ECAB5A3705687.tpdila13v_3?idSectionTA $=$ LEGISCTA000006135862\&cidTexte $=$ LEGITEXT0 00006070716\&dateTexte $=20161004>$. Acesso em: 04 out. 2016.

FRANCESCHINI, José Inácio. A lei e o foro de eleição em tema de contratos internacionais. In: RODAS, João Grandino (Coord.). Contratos Internacionais. 3. ed. rev. atual. e ampl. São Paulo: Revista dos Tribunais, 2002. p. 67-75.

GARCIA JUNIOR, Armando Alvares. Lei aplicável aos contratos internacionais. 2. ed. São Paulo: Aduaneiras, 2004.

HANSFORD, Thomas G.; SPRIGGS II, James F. The Politics of Precedent on the U.S. Supreme Court. Princeton: Princeton University Press, 2006.

HCCH. Convention of 30 June 2005 on Choice of Court Agreements. Disponível em: <https://www.hcch.net/ en $/$ instruments $/$ conventions $/$ full-text $/$ ?cid $=98>$. Acesso em: 04 out. 2016.

$\mathrm{HCCH}$. Introduction to the Hague Principles on Choice of Law in International Commercial Contracts. Disponível em: $<$ https://www.hcch.net/pt/instruments/conventions/ full-text/?cid=135>. Acesso em: 04 out. 2016.

KUCK, Lea; HELLMANN, Betsy. International Cases Court of Appeals Decided in 2012, Looking Ahead to 2013. New York Law Journal, v. 49, n. 46, p. 1-3, 2013.

LOAN MARKET ASSOCIATION. Disponível em: <http://www.lma.eu.com>. Acesso em: 05 out. 2016.

MARQUES, Cláudia Lima. Ensaio para uma introdução ao Direito Internacional Privado. In: DIREITO, Carlos Alberto Menezes; TRINDADE, Antônio Augusto Cançado; PEREIRA, Antonio Celso Alves. (Coord.). Novas perspectivas do direito internacional contemporâneo: Estudos em homenagem ao professor Celso D. de Albuquerque Mello. Rio de Janeiro: Renovar, 2008.

NARDI, Marcelo de. Eleição de foro: Uma visão brasileira. In: RODAS, João Grandino (Coord.). Contratos Internacionais. 3. ed. rev. atual. e ampl. São Paulo: Revista dos Tribunais, 2002.

ORGANIZAÇÃO DOS ESTAOS AMERICANOS. Convenção Interamericana sobre Direito Aplicável aos Contratos Internacionais. Disponível em: <http://www.oas.org/juridico/portuguese/treaties/b-56.htm>. Acesso em: 04 out. 2016. 
PORTUGAL. Lei n. ${ }^{\circ}$ 41/2013, de 26 de junho. Disponível em: <http://www.pgdlisboa.pt/leis/lei_mostra_articulado.php?nid=1959\&tabela=leis $>$. Acesso em: 04 out. 2016.

RASHKOVER, Barry W. Title 14 New York Choice of Law Rule for Contractual Disputes: Avoiding the Unreasonable Results. Cornell Law Review, v. 71, p. 227-248, 1985.

REESE, Willis. Conflict of Laws and the Restatement Second. 28 Law and Contemporary Problems. p. 679-699, 1963. Disponível em: <http://scholarship.law.duke. edu/lcp/vol28/iss4/2>. Acesso em: 04 out. 2016.

RIBEIRO, Marilda Rosado de Sá. Batalha das formas e negociação prolongada nos contratos internacionais. In: RODAS, João Grandino (Coord.). Contratos Internacionais. 3. ed. rev. atual. e ampl. São Paulo: Revista dos Tribunais, 2002. p. 251-282.

ROCHA, Dinir Salvador Rios de. Contrato de empréstimo internacional. São Paulo: Saraiva, 2013.

RUHL, Giesela. Party Autonomy in the Private International Law of Contracts: Transatlantic Convergence and Economic Efficiency. CLPE Research Paper 4/2007, v. 3, n. 1, p. 1-41, 2007.

SOUZA JUNIOR, Lauro da Gama. Autonomia da vontade nos contratos internacionais no Direito Internacional Privado brasileiro: Uma leitura constitucional do artigo $9^{\circ}$ da Lei de Introdução ao Código Civil em favor da liberdade de escolha do direito aplicável. In: TIBURCIO, Carmen; BARROSO, Luís Roberto (Org.). O direito internacional contemporâneo: estudos em homenagem ao professor Jacob Dolinger. Rio de Janeiro: Renovar, 2006.

SYMEONIDES, Symeon C. The American choice-of-law revolution in the courts: today and tomorrow. Recueil des Cours de la Académie de Droit International, tome 35, 2002.

TESHEINER, José Maria. Jurisdição territorial nos Estados Unidos da América do Norte e Competência Internacional e de Foro no Brasil. Revista Eletrônica de Direito Processual, Rio de Janeiro, v. 13, p. 259-274, 2014.

THE LOAN SYNDICATIONS AND TRADING ASSOCIATION. Disponível em: <http://www.lsta. org >.Acesso em: 05 out. 2016.

TIBURCIO, Carmen. A arbitragem como meio de solução de litígios comerciais internacionais envolvendo o petróleo e uma breve análise da cláusula arbitral da sétima rodada de licitações da ANP. Revista de Arbitragem e Mediação, São Paulo, v. 3, n. 9, p. 78-98, abr./jun. 2006. TIBURCIO, Carmen. A eleição de foro estrangeiro e o judiciario brasileiro. Revista de Arbitragem e Mediação, São Paulo, v. 6, n. 21, p. 84-113, abr./jun. 2009.

U.S. Restatement (Second) of Conflicts of Law. Disponível em: <http://www.kentlaw.edu/perritt/conflicts/rest187.html>. Acesso em: 05 out. 2016.

UNIAO EUROPEIA. Regulamento (ce) n.o 593/2008 do Parlamento Europeu e do Conselho de 17 de junho de 2008. Disponível em: <http://eur-lex.europa.eu/LexUriServ/LexUriServ.do?uri=OJ:L:2008:177:0006:0016:PT: PDF>. Acesso em: 04 out. 2016.

UNIÃO EUROPÉIA. Regulamento (UE) $n^{\circ} 1215$ do Parlamento Europeu e do Conselho de 12 de dezembro 2012. Disponível em: <http://eur-lex.europa.eu/LexUriServ/LexUriServ.do?uri=OJ:L:2012:351:0001:0032:pt: PDF>. Acesso em: 04 out. 2016.

US NY COURTS. IRB-Brasil Resseguros, S.A. v. Inepar Investments, S.A. Opinion of Chief Juge, Lippman, p. 1-8, 2012. Disponível em: <http://www.nycourts. gov/ctapps/Decisions/2012/Dec12/191opn12.pdf>. Acesso em: 03 out. 2016.

VASCONCELOS, Raphael. Premissas Fundamentais do Direito Internacional Privado. In: TIBURCIO, Carmen; MENEZES, Wagner; VASCONCELOS, Raphael (Org.). Panorama do Direito Internacional Privado Atual e outros Temas Contemporâneos. Belo Horizonte: Arraes Editores, 2015. p. 34-54.

WIGHT, Richard; COOKE, Warren; GRAY, Richard. The LSTA's Complete Credit Agreement Guide. Nova York: McGraw Hill, 2009.

XAVIER JUNIOR, Ely Caetano; CASTRO, Emília Lana de Freitas. A competência internacional e a eleição de foro no projeto do novo código de processo civil brasileiro. Revista do Instituto do Direito Brasileiro, Lisboa, ano 2, n. 8, p. 7985-8022, 2013. Disponível em: < http:// www.cidp.pt/publicacoes/revistas/ridb/2013/08/201 3_08_07985_08022.pdf>. Acesso em: 03 out. 2016.

XAVIER, Mônica Antão. Internacionalização de Empresas e o Direito Internacional dos Investimentos. In: ROSADO, Marilda (Org.). Direito Internacional dos Investimentos. Rio de Janeiro: Renovar, 2014. v. 1, p. 303-328. 
Para publicar na Revista de Direito Internacional, acesse o endereço eletrônico www.rdi.uniceub.br ou www.brazilianjournal.org.

Observe as normas de publicação, para facilitar e agilizar o trabalho de edição. 